Dominique LoUPPE ${ }^{1,2}$

N'klo OUATTARA ${ }^{3}$

Anatole N'GUESSAN KANGA4

Irié $\mathrm{ZO}-\mathrm{BI}^{5}$

Fabrice TIÉOULÉ ${ }^{6}$

Assandé АновA ${ }^{4}$

Brahima CoulibalY ${ }^{4}$

Bruno HÉRAULT ${ }^{1,2,5}$

${ }^{1}$ CIRAD

UPR Forêts et Sociétés

34398 Montpellier

France

${ }^{2}$ Forêts et Sociétés

Univ Montpellier, CIRAD

Montpellier

France

${ }^{3}$ Université Péléforo Gon Coulibaly

BP 1328, Korhogo

Côte d'Ivoire

${ }^{4}$ Centre national de recherche agronomique (CNRA)

08 BP 33, Abidjan 08

Côte d'Ivoire

${ }^{5}$ Institut national polytechnique Félix

Houphouët-Boigny (INPHB)

Département de formation et

de recherche en eaux, forêts et

environnement

Yamoussoukro

Côte d'Ivoire

${ }^{6}$ Société de développement des forêts

(Sodefor)

Boulevard François Mitterrand

01 BP 3770, Abidjan

Côte d'Ivoire

\section{Auteur correspondant / \\ Corresponding author: \\ Dominique Louppe - \\ dominique.louppe@cirad.fr}

\title{
Vingt-deux espèces d'arbres autochtones plantées en arboretum à Korhogo au nord de la Côte d'Ivoire : trois décennies de suivi
}

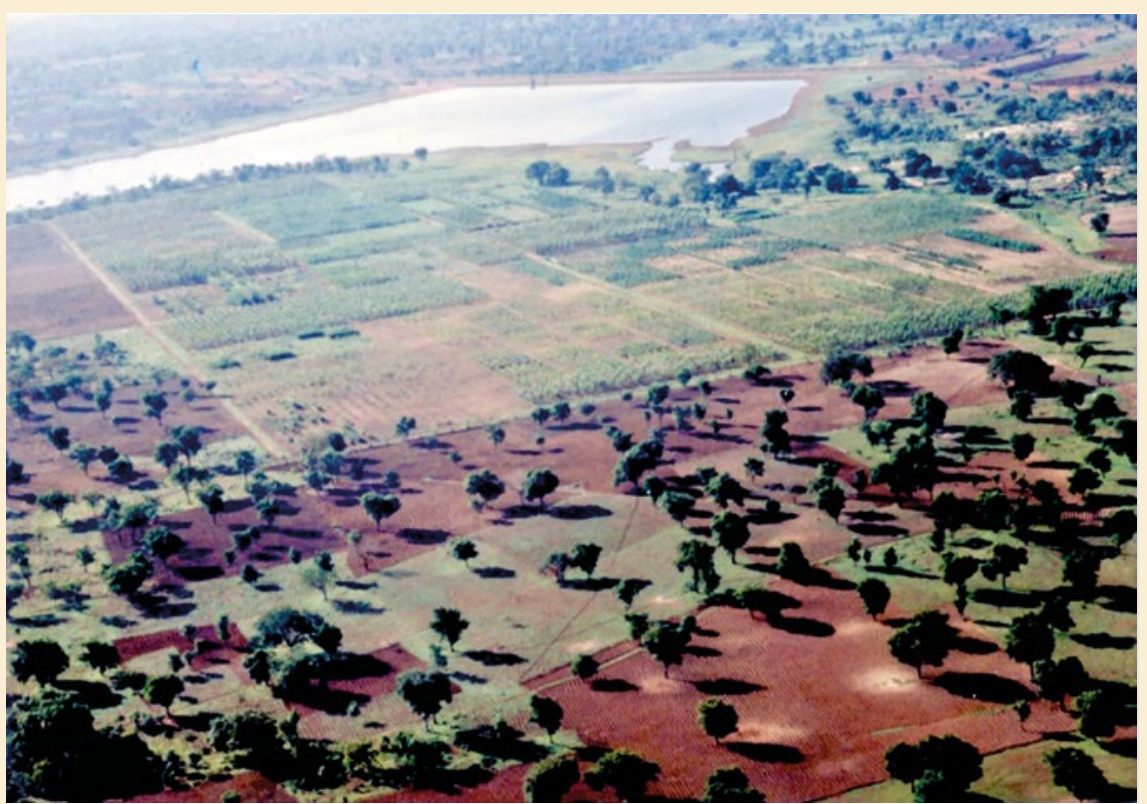

Photo 1.

À l'avant-plan, les terres cultivées par les agriculteurs en bordure de la station, en plan moyen les parcelles expérimentales de 1988 et 1989, et à l'arrière-plan le lac de barrage destiné à irriguer les cultures en aval. Les arbres présents dans les terres de culture sont principalement des karités avec quelques nérés et de temps en temps une autre espèce conservée pour ses usages fruitiers, fourragers ou médicinaux, voire symboliques ou comme marqueur de propriété. Les taches claires dans les terres labourées ainsi que celles vert clair dans les parcelles ensemencées sont des emplacements de termitières anciennes plus ou moins actives. Ces termitières sont toujours associées à un arbre ou à l'emplacement d'un arbre abattu, ce qui montre l'étroite relation entre termites et arbres.

In the foreground, the land cultivated by the farmers on the edge of the station, in the middle ground the experimental plots of 1988 and 1989, and in the background the dam lake intended to irrigate the crops downstream. The trees in the croplands are mainly shea trees with a few neres and occasionally another species retained for its fruit, fodder or medicinal uses, or even as a symbolic or property marker. The light patches in the ploughed land and the light green patches in the sown plots are sites of old termite mounds that are more or less active. These termite mounds are always associated with a tree or the site of a felled tree, which shows the close relationship between termites and trees.

Photo D. Louppe, début juin 1990.

Doi : $10.19182 /$ bft2021.348.a36399 - Droit d'auteur (C 2021, Bois et Forêts des Tropiques - (c) Cirad - Date de soumission : 28 septembre 2020 ; date d'acceptation : $1^{\text {er }}$ avril 2021 ; date de publication : 18 juin 2021.
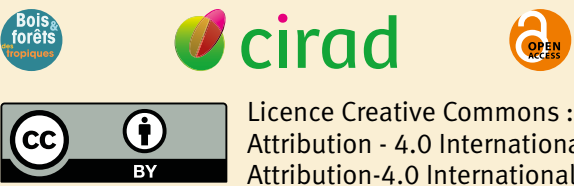

Citer l'article / To cite the article

Louppe D., Ouattara N'K., N'guessan Kanga A., Zo-Bi I., Tiéoulé F., Ahoba A., Coulibaly B., Hérault B., 2021. Vingt-deux espèces d'arbres autochtones plantées en arboretum à Korhogo au nord de la Côte d'Ivoire : trois décennies de suivi. Bois et Forêts des Tropiques, 348 : 79-105. Doi : https://doi.org/10.19182/bft2021.348.a36399 


\section{RÉSUMÉ}

\section{Vingt-deux espèces d'arbres autochtones plantées en arboretum à Korhogo au nord de la Côte d'Ivoire : trois décennies de suivi}

En Afrique tropicale, dans les plantations forestières, la majorité des espèces autochtones ont été délaissées au profit d'espèces exotiques à croissance initiale rapide. Cette tendance est encore plus marquée dans les zones soudanienne et soudano-guinéenne à longue saison sèche. Ainsi s'explique le manque de connaissances sur les potentialités et la sylviculture des espèces d'arbres autochtones ou "locales ». Pour contribuer à l'acquisition de ces connaissances indispensables, un arboretum de 2,56 ha a été installé en 1990 à proximité de Korhogo dans le nord de la Côte d'Ivoire. Sa particularité réside dans la mise en place de grandes parcelles de $1596 \mathrm{~m}^{2}$ avec 224 plants par espèce afin d'y mener une sylviculture qui conserverait de 10 à 16 arbres adultes de chaque espèce, exploitables notamment pour le bois d'œuvre, au terme de la révolution. Par manque de maîtrise des techniques de pépinière pour certaines espèces, seules 12 espèces sur 22 ont été plantées avec les 224 plants prévus au départ. Les résultats sont présentés pour l'ensemble des espèces testées, aussi bien en pépinière qu'en plantation. Cet arboretum a été régulièrement suivi jusqu'en 1999 puis ne l'a plus été en raison des évènements politiques qui ont perturbé la bonne administration du pays. Une campagne de mesures a été diligentée en novembre 2019. Elle a notamment permis de tirer des conclusions intéressantes sur l'aptitude de 15 espèces à croître en peuplements équiennes monospécifiques, dont deux (Pterocarpus erinaceus Poir. et Anogeissus leiocarpa (DC.) Guill. \& Perr.) qui montrent une productivité remarquable. L'ensemble des données recueillies depuis la récolte des graines et tout au long de la vie de l'arboretum sont présentées ici et discutées dans l'espoir que les sylviculteurs de cette zone phytogéographique en tirent le meilleur profit. Les enseignements acquis doivent servir à la restauration des forêts et des paysages grâce aux reboisements auxquels les États se sont engagés pour lutter contre les variations climatiques, la perte de biodiversité et la dégradation des services écosystémiques aux populations.

Mots-clés : arboretum, espèces locales, espèces natives, croissance, bilan à 30 ans, zone soudano-guinéenne, Côte d'Ivoire.

\section{ABSTRACT}

\section{Three decades of monitoring 22 native tree species planted in an arboretum in Korhogo in northern Côte d'Ivoire}

In forest plantations in tropical Africa, most native species have been left aside in favour of exotic species with initially rapid growth rates. This tendency is even more marked in the Sudanian and Sahelian zones with a long dry season, and explains the lack of knowledge on the potential of native or "local" tree species and suitable sylvicultural methods. To contribute to the acquisition of this essential knowledge, a 2.56 ha arboretum was established in 1990 in the Korhogo area in northern Côte d'Ivoire. A particular feature lies in the establishment of large parcels $\left(1,596 \mathrm{~m}^{2}\right)$ with 224 saplings of each species. The aim was to allow sylvicultural treatment that would conserve 10 to 16 adult trees of each species, in particular for their timber, by the end of each rotation. Because nursery techniques for some of the species were insufficiently mastered, the 244 saplings per species initially planned were only planted for 12 of the 22 species. The results are shown for all of the species tested, both in the nursery and once planted out. This arboretum was regularly monitored until 1999, when proper management was disrupted by political upheaval in the country. A measurement campaign was set in motion in November 2019, which brought interesting conclusions as to the aptitude for growth of 15 species in even-aged single-species stands, two of which (Pterocarpus erinaceus Poir. and Anogeissus leiocarpa (DC.) Guill. \& Perr.) show outstanding productivity. All of the data collected as from seed harvesting and throughout the life of the arboretum are presented and discussed here, in the hope that this will be of benefit to foresters in this phytogeographical area. The lessons learned should be applied to forest and landscape restoration through the reforestation commitments made by countries to tackle climate change, biodiversity loss and the degradation of ecosystem services to populations.

Keywords: arboretum, local species, native species, growth, 30-year assessment, Sudano-Guinean zone, Côte d'Ivoire.

\section{RESUMEN}

\author{
Veintidós especies arbóreas autóctonas \\ plantadas en un arboreto de Korhogo, \\ al norte de la Costa de Marfil: \\ tres décadas de seguimiento
}

En el África tropical, la mayor parte de las especies autóctonas se han abandonado en las plantaciones forestales y se han favorecido las especies exóticas de rápido crecimiento inicial. Esta tendencia es aún más pronunciada en las zonas sudanesa y sudano-guineana, con largas estaciones secas. Esto explica la falta de conocimiento sobre el potencial y la silvicultura de las especies arbóreas autóctonas o «locales». Para fomentar estos conocimientos indispensables, en 1990 se creó un arboreto de 2,56 hectáreas cerca de Korhogo, en el norte de la Costa de Marfil. Su particularidad reside en el establecimiento de grandes parcelas de $1596 \mathrm{~m}^{2}$ con 224 plántulas por especie para llevar a cabo una silvicultura que mantenga de 10 a 16 árboles adultos de cada especie, y con un aprovechamiento final especialmente en madera de construcción. Debido al poco dominio de las técnicas de vivero para ciertas especies, solo se plantaron 12 de las 22 especies con las 224 plantas previstas inicialmente. Se presentan los resultados para las especies que se probaron, tanto en el vivero como en la plantación. Este arboreto fue supervisado regularmente hasta 1999, cuando los acontecimientos políticos que afectaron a la administración del país impidieron su seguimiento. En noviembre de 2019 se llevó a cabo una campaña de mediciones que, entre otras cosas, permitió obtener interesantes conclusiones sobre la capacidad de 15 especies para crecer en masas monoespecíficas de edad uniforme, dos de las cuales (Pterocarpus erinaceus Poir. y Anogeissus leiocarpa (DC.) Guill. $\&$ Perr.) muestran una notable productividad. Aquí se presentan todos los datos obtenidos desde la recolección de las semillas y a lo largo de la vida del arboreto, y se analizan con la esperanza de que los silvicultores de esta zona fitogeográfica los aprovechen al máximo. Las lecciones aprendidas deben utilizarse para restaurar los bosques y los paisajes mediante la reforestación a la que se han comprometido los estados para combatir el cambio climático, la pérdida de biodiversidad y la degradación de los servicios ecosistémicos para las personas.

Palabras clave: arboreto, especies locales, especies autóctonas, crecimiento, evaluación a 30 años, zona sudano-guineana, Costa de Marfil. 


\section{Recherches sur les espèces soudano-guinéennes en Afrique de l'Ouest}

Dans les années 1980, dans les zones soudanienne et soudano-guinéenne d'Afrique de l'Ouest, les services forestiers et la recherche forestière avaient largement oublié les espèces autochtones au profit des espèces exotiques dont la croissance juvénile spectaculaire devait permettre de répondre rapidement à la demande croissante en bois énergie. Cependant, beaucoup de ces exotiques, malgré une croissance initiale remarquable, n'ont pas toujours bien répondu aux conditions du milieu, surtout dans les conditions difficiles du Sahel et de la zone soudanienne. Malheureusement, ces échecs n'ont pas été publiés.

Les arboretums d'espèces autochtones mis en place jusque dans les années 1960, dans plusieurs pays de la zone, n'ont pas été suivis régulièrement ou ont disparu, et avec eux de nombreuses informations scientifiques et pratiques qui demandent une vingtaine d'années, au minimum, pour être à nouveau rassemblées. Les causes en sont généralement le manque de moyens financiers et les mouvements de personnels dont le départ des responsables et leur remplacement par des agents travaillant sur de nouveaux sujets.

Au moins 91 espèces d'arbres autochtones différentes ont été testées en plantation dans les zones sahélienne, soudanienne et soudano guinéenne du Burkina Faso, du Cameroun, de Côte d'Ivoire, du Niger et du Sénégal (Louppe, 1993). En zone soudano-guinéenne, un nombre beaucoup plus réduit d'espèces ont été installées dans des essais de comportement, en Basse Casamance au Sénégal, près de Sikasso au Mali et de Bobo-Dioulasso au Burkina Faso. En 1988, la station forestière de Lataha près de Korhogo dans le nord de la Côte d'Ivoire venait compléter ces dispositifs de recherche.

Au Sénégal, dans la forêt des Bayottes, 19 espèces autochtones ont été plantées entre 1977 et 1980 mais les dernières données de Vincenti datent de 1986, quand les plantations avaient à peine neuf ans. Les troubles qui ont agité la Casamance n'ont plus permis d'accéder aux dispositifs. En 1995, Roussel décrit les techniques de pépinière et de plantation de ces espèces mais pas leur croissance.

Au Mali, des essais ont été installés dans les forêts de Farako et de Zangasso, près de Sikasso, avec une pluviométrie respectivement de l'ordre de 1100 et de 900 mm/ an. En 1997, Cuny et al. ont produit des fiches techniques sur 24 espèces autochtones dont le comportement en pépinière avait bien été étudié. Les résultats des plantations et des semis directs au champ au Mali ne concernaient que 11 espèces âgées de sept ans au maximum, les autres données présentées provenaient du Burkina Faso et/ou de la station de Lataha.

Au Burkina Faso, les expérimentations installées par le CTFT au PK9 de la route de Bobo-Dioulasso à Dindéresso ont été détruites dans les années 1980 et remplacées par de nouvelles plantations expérimentales de Faidherbia albida en 1985-1987 et 1990, Ceiba pentandra et Parkia biglobosa en 1986, Khaya senegalensis en 1989, Anogeissus leiocarpa, Tamarindus indica et Vitex sp. en 1990 (Billand et Ousmane, 1991 ; Peltier, 1993).

Au Nord-Cameroun, un nombre limité d'espèces a été installé en petites parcelles entre 1989 et 1992 dans la zone où la pluviométrie dépasse $1000 \mathrm{~mm}$. Les dernières mesures datent de 2002 (Peltier, 1987 ; Hautdidier et al., 2002).

De toutes ces expérimentations, celles de Côte d'Ivoire semblent être les seules à subsister : des autres dispositifs, on ne trouve pas de traces plus récentes que celles citées ci-dessus, que ce soit sur Internet avec le moteur de recherche Google Scholar ou sur les sites web des instituts de recherche concernés, pas davantage dans la littérature grise du Cirad.

\section{À l'origine de l'arboretum 90-01 de Lataha}

La station de recherche forestière Kamonon Diabaté à Lataha - du nom de son promoteur - a été créée en 1988 grâce à des financements européens dans le cadre d'un partenariat entre la Côte d'Ivoire et la France, afin de développer une recherche forestière et agroforestière dans le Nord du pays (Louppe et al., 1991, 1993, 1994, 1995 ; Louppe et Ouattara, 1993, 1996a, b). Dès la première année, de nouveaux arboretums d'espèces locales y ont été installés. Après quatre ans, 50 espèces locales différentes avaient déjà été testées en plantation (Louppe et al., 1992). Ces arboretums avaient pour objectif de répondre à plusieurs questions :

- Quelles sont les techniques de pépinière adaptées à chaque espèce : comment faire germer les graines ? À quelle taille planter les jeunes plants au champ ? Ces espèces nécessitent-elles d’être associées à des symbioses dès la pépinière...?

- À quelle vitesse croît chaque espèce, s'installent-elles rapidement ou pas, à quel moment intervient l'optimum de production, sont-elles aptes à vivre en peuplements monospécifiques ou pas?

- Quelles sont les utilisations potentielles de chaque espèce à long terme : bois d'œuvre, bois de feu ou de service, arbres agroforestiers, haies vives, brise-vent, fruits, fourrage... ?

- Quelle sylviculture faut-il leur appliquer : éclaircie, mode d'exploitation, régénération?

Les réponses à ces questions devaient permettre de choisir les espèces pour le reboisement ou l'agroforesterie, voire pour des plantations urbaines ou ornementales.

Même si les arboretums ne peuvent répondre totalement à l'ensemble de ces interrogations, ils permettent de récolter de nombreuses informations de base sur un maximum d'espèces autochtones. Rassembler ces connais- 
sances préliminaires permet d'orienter des dispositifs statistiques plus lourds et de définir précisément leurs objectifs.

Si les parcelles ont une taille suffisante, les arboreespèce au cours de sa croissance, par exemple l'apparition éventuelle d'une concurrence intraspécifique induisant une forte mortalité qui caractérise les espèces non grégaires inadaptées aux plantations monospécifiques ou aux plantations trop denses.

Fin des années 1980, en dehors des flores (Aubréville, 1950 ; Berhaut, 1967 ; Geerling, 1982), les connaissances facilement accessibles sur les espèces locales soudano-guinéennes en plantation étaient fort limitées (Giffard, 1974 ; von Maydell, 1983). En 1990, tout ou presque semblait ou restait donc à faire.

Il fallait porter davantage d'attention aux espèces autochtones, notamment dans le but d'en conserver la diversité menacée par les activités humaines et la conversion des espaces boisés en terres agricoles, d'où la mise en place, en 1990, de l'arboretum 90-01 de Lataha, objet de cet article.

En 2020, ces plantations existent encore malgré une absence de suivi pendant près de 20 ans. Les dernières mesures de 2019, à 29 ans, ont permis de rassembler des connaissances nouvelles sur les espèces autochtones plantées et d'en tirer des recommandations pour de futures plantations et la restauration des forêts et des paysages.

\section{Matériel et méthode}

\section{La zone d'étude}

La station de recherche Kamonon Diabaté, d'une superficie de 100 ha, est située en Côte d'Ivoire à une vingtaine tums permettent de déterminer le comportement de chaque

de kilomètres au nord-est de la ville de Korhogo par 9०34' N et $5^{\circ} 35^{\prime} \mathrm{O}$ (figure 1 ) sur les terres du village de Lataha. Elle est gérée par le Centre national de recherche agronomique (CNRA) de Côte d'Ivoire qui a pris la suite de l'Institut des forêts et du Centre technique forestier de Côte d'Ivoire qui a créé la station. Les terres ont été cédées gracieusement et de manière informelle - il n'y a pas eu transfert de titre de propriété - par les villageois de Lataha en 1987. La contrepartie était de recruter de la main-d'œuvre sur place. En 1999, lors d'une grande fête à l'occasion du départ du chercheur du CTFT Dominique Louppe, un accord verbal a été négocié avec les notables de Lataha et de Séridiakaha. Cet accord précisait que la station était un site à protéger mais que l'accès y était autorisé pour venir chercher de l'eau potable et pour récolter les herbes à éléphant qui servent à couvrir les toitures et faire des nattes. En échange, tous les arbres devaient être protégés y compris ceux qui n'avaient pas été plantés. La station est aussi un lieu où la chasse est interdite afin de permettre aux animaux de se reproduire ; ils peuvent être chassés dès lors qu'ils sortent de la station. Cet accord verbal a été respecté par la population avoisinante et par le CNRA. On peut ainsi penser que cet accord informel explique le bon état de conservation des plantations expérimentales et des espaces boisés naturels de cette station.

\section{Pédologie}

La station, dont l'altitude moyenne est de $380 \mathrm{~m}$, est dominée par un dôme granitique affleurant qui, en suivant la toposéquence, est entouré par des sols gravillonnaires superficiels, puis des sols gravillonnaires profonds à texture argilo-limono-sableuse pour arriver à des limons sableux en bas de pente. Ces sols sont légèrement acides $(\mathrm{pH}$ de 5,4 à 6), pauvres en matière et azote organiques et fortement désaturés (taux de saturation de 21 à $54 \%$ ), pauvres en calcium, magnésium, potassium et phosphore. Ils sont légèrement carencés en bore (de 0,25 à $0,55 \mathrm{ppm}$ ). Les humidités à $\mathrm{pF} 2,5$ et 4,2 sont faibles, indiquant une capacité de rétention de 1,7 à 3,4 \% (Louppe et Ouattara, 1990). L'arboretum a été installé en périphérie du dôme granitique affleurant en évitant les sols gravillonnaires superficiels.

\section{Station de recherche forestière de Lataha (Korhogo)}

Végétation de la Côte d'Ivoire

Figure 1.

a) Localisation de la station de Lataha en Côte d'Ivoire. Les différentes couleurs représentent les différents types de végétation initiale dans le pays. La zone jaune dans laquelle la station est installée est celle des savanes soudano-guinéennes. b) Vue aérienne de la station en janvier 2020. Le lac de barrage est particulièrement haut, les pluies de 2019 ayant été largement supérieures à la normale (source : Google Earth).

a) Location of the Lataha station in Côte d'Ivoire. The different colours represent the different types of initial vegetation in the country. The yellow zone in which the station is located is the Sudano-Guinean savannah. b) Aerial view of the station in January 2020. The dam lake is particularly high, as the 2019 rains were much higher than normal (source: Google Earth). 
du mois le plus froid) à $39^{\circ} \mathrm{C}$ (maximum moyen du mois le plus chaud) avec une moyenne annuelle de $26,5^{\circ} \mathrm{C}$ (figure 2a). Les précipitations sont de l'ordre de $1300 \mathrm{~mm} / \mathrm{an}$ avec une grande variabilité interannuelle (figure $2 b$ ). L'année est divisée en une saison des pluies de mai à septembre (les précipitations ne sont supérieures à l'ETP que pendant 4 mois) et une saison sèche d'octobre à avril avec le vent de l'harmattan, surtout en décembre-janvier.

La variabilité du climat aux alentours de Korhogo est très importante. Boko-Koiadia et al. (2016) ont décrit les évènements climatiques extrêmes survenus dans la région pendant la décennie 2000-2010 : très fortes pluies en 2003, sécheresse en 2004-2005 avec l'assèchement des points d'eau (barrages, rivières, puits, pénurie d'eau potable en ville), puis inondation en 2006-2007.

Les très fortes pluies de 2019 (1 472 mm ; Harris et al., 2020) ont entraîné une forte érosion, jusqu'alors jamais observée dans les terres agricoles mais pas dans les parcelles boisées (les gabions du pont de la station ont été en partie emportés et le lit du ruisseau a été fortement entaillé). Le barrage qui jouxte la station a été rempli à ras bord, un niveau jamais atteint (figure 1 ).

\section{Végétation initiale}

La majeure partie de la station était cultivée et la végétation modelée par l'homme : parcs à karité (Vitellaria paradoxa C.F. Gaertn.) et à néré (Parkia biglobosa (Jacq.) R. Br. ex G. Don.) (photo 1). Quelques vestiges des formations forestières anciennes, quoique dégradées, subsistaient sur les sols trop superficiels ou entre les blocs granitiques. On y rencontre entre autres Isoberlinia doka Craib \& Stapf, Afzelia africana Sm. ex Pers., Anogeissus leïocarpa (DC) Guill. \& Perr., Daniellia oliveri (Rolfe) Hutch. \& Dalziel, Terminalia sp., Anthonotha crassifolia (Baill.) J. Leonard...

\section{Provenance du matériel végétal}

L'origine des graines utilisées pour la création de l'arboretum 90-01 est présentée en détail dans le tableau I.

\section{Prétraitement des semences et germination}

Les graines de la majorité des espèces adaptées aux zones sèches présentent une dormance tégumentaire qui garantit le succès de la régénération naturelle par semis. En effet, si toutes les graines germent simultanément dès que l'humidité atmosphérique augmente, ou dès la première pluie, puis si une sécheresse survient, tous les semis risquent de disparaître et la régénération naturelle est un échec. La dormance permet d'étaler les germinations pour limiter ce risque mais pose un problème en pépinière où une germination rapide et homogène est recherchée. Pour lever cette dormance, le pépiniériste doit traiter les graines avant le semis. Ce prétraitement sert à rendre les téguments perméables à l'eau pour favoriser le gonflement de la graine et le développement de la radicule puis des racines et de l'épicotyle. Un bon prétraitement permet d'accélérer et de regrouper les germinations en quelques jours seulement. Les prétraitements qui ont été utilisés diffèrent selon les espèces et la dormance des graines : trempage dans l'acide sulfurique concentré (94\%) plus ou moins longuement, ébouillantage qui consiste à plonger un volume de graines dans deux volumes d'eau portés à ébullition que l'on laisse refroidir, trempage dans l'eau froide pendant 12 ou $24 \mathrm{~h}$ associé ou non avec les deux traitements précédents et la scarification mécanique pour blesser les téguments de la graine. Les prétraitements adoptés sont présentés dans le tableau II. Tous n'ont pas donné les résultats escomptés.

\section{Éducation en pépinière}

Les conteneurs utilisés sont des pots souples en polyéthylène d'une hauteur de $20 \mathrm{~cm}$ et de $9 \mathrm{~cm}$ de diamètre une fois remplis. Ils sont perforés à la base pour assurer un bon drainage. Le substrat de remplissage est un mélange de terre sablo-limoneuse et de terreau - récolté dans des zones boisées voisines -

\section{frais}
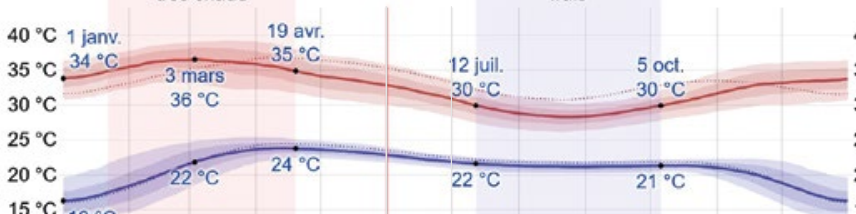

$16^{\circ} \mathrm{C}$

${ }^{\circ} \mathrm{C}$

$5{ }^{\circ} \mathrm{C}$

$0{ }^{\circ} \mathrm{C}$

$-5^{\circ} \mathrm{C}$

$-10^{\circ} \mathrm{C}$

$-15^{\circ} \mathrm{C}$

$-20^{\circ} \mathrm{C}$

Figures $\mathbf{2 a}$ et $\mathbf{2 b}$.

Températures (a) et pluviométrie (b) pour la période 1980 à 2016 (source : Weather Spark,

https://fr.weatherspark.com/v/34013/Météo-habituelle-à-Korhogo-Côte-d'Ivoire).

a) La température moyenne quotidienne maximale (ligne rouge) et minimale (ligne bleue), avec bandes du $25^{\mathrm{e}}$ au $75^{\mathrm{e}}$ percentile et du $10^{\mathrm{e}}$ au $90^{\mathrm{e}}$ percentile. Les lignes fines pointillées sont les températures moyennes perçues correspondantes.

b) La quantité de pluie moyenne (ligne continue) accumulée au cours d'une période glissante de 31 jours centrée sur le jour en question, avec bandes du $25^{\mathrm{e}}$ au $75^{\mathrm{e}}$ percentile et du $10^{\mathrm{e}}$ au $90^{\mathrm{e}}$ percentile.

a) The daily average maximum temperature (red line) and minimum temperature (blue line), with bands from the $25^{\text {th }}$ to the $75^{\text {th }}$ percentile and from the $10^{\text {th }}$ to the $90^{\text {th }}$ percentile. The thin dotted lines are the corresponding perceived mean temperatures.

b) The average rainfall amount (solid line) accumulated over a 31-day rolling period centred on the day in question, with bands from the $25^{\text {th }}$ to $75^{\text {th }}$ percentile and $10^{\text {th }}$ to $90^{\text {th }}$ percentile. 
Tableau I.

Arboretum 90-01 Lataha : espèces plantées et origine des graines.

Arboretum 90-01 Lataha: species planted and origin of seeds.

\begin{tabular}{|c|c|c|c|c|}
\hline Espèces plantées & $\begin{array}{l}\text { Nombre } \\
\text { de plants }\end{array}$ & $\begin{array}{l}\text { Lieux de récolte } \\
\text { des graines }\end{array}$ & $\begin{array}{l}\text { Mois de } \\
\text { récolte }\end{array}$ & $\begin{array}{l}\text { Nombre de } \\
\text { semenciers }\end{array}$ \\
\hline Acacia polyacantha Willd. & 224 & Sinématiali & $12 / 1989$ & 3 \\
\hline Acacia sieberiana DC. & 224 & Sinématiali & $12 / 1989$ & 4 \\
\hline Afzelia africana Sm. ex Pers. & 224 & $\begin{array}{l}\text { Bobo-Doulasso } \\
\text { (Burkina Faso) } \\
\text { et Lataha }\end{array}$ & - & - \\
\hline Albizia zygia (DC.) J.F. Macbr. & 224 & Lataha & $01 / 1990$ & 2 \\
\hline Anogeissus leiocarpa (DC.) Guill. \& Perr. & 112 & Lataha & $12 / 1989$ & 3 \\
\hline Balanites sp. & 14 & Péni, Burkina Faso & $12 / 1989$ & 2 \\
\hline Blighia sapida K.D. Koenig & 224 & Lataha & $\begin{array}{l}08 / 1989 \\
05 / 1990\end{array}$ & 5 \\
\hline Ceiba pentandra (L.) Gaertn. & 224 & Korhogo & $02 / 1990$ & 3 \\
\hline Cola cordifolia (Cav.) R. Br. & 112 & Station Lataha & 05/1990 & 2 \\
\hline Daniellia oliveri (Rolfe) Hutch. \& Dalziel & 224 & Seridiakaha & $03 / 1990$ & 2 \\
\hline Detarium microcarpum Guill. \& Perr. & 224 & $\begin{array}{l}\text { CNSF - Burkina } \\
\text { Faso, Bobo-Dioulasso. }\end{array}$ & - & - \\
\hline Faidherbia albida (Delile) A. Chev. & 224 & Nagounkaha & 02/1990 & 3 \\
\hline Ficus exasperata Vahl & 84 & Lataha & 05/1990 & 2 \\
\hline Parkia biglobosa (Jacq.) R. Br. ex G. Don & 224 & Lataha & 04/1990 & 2 \\
\hline Pericopsis laxiflora (Benth.) Meeuwen & 128 & Station Lataha & $11 / 1989$ & 3 \\
\hline Pterocarpus erinaceus Poir. & 112 & Lataha & $03 / 1990$ & 2 \\
\hline Spondias mombin L. & 168 & Lataha & \multicolumn{2}{|c|}{$\begin{array}{l}158 \text { boutures et } 10 \text { plants } \\
\text { issus de graines }\end{array}$} \\
\hline Sterculia setigera Delile & 224 & Lataha & $11 / 1989$ & 2 \\
\hline Tamarindus indica L. & 224 & Station Lataha & $12 / 1989$ & 4 \\
\hline Terminalia macroptera Guill. \& Perr. & 112 & Katégué & $12 / 1989$ & 3 \\
\hline Terminalia schimperiana Hochst. & 56 & Station Lataha & - & 2 \\
\hline Vitex doniana Sweet & 64 & Station Lataha & 08/1989 & - \\
\hline Total : 22 espèces plantées & 3650 & \multicolumn{3}{|c|}{ Surface plantée : 2,56 ha* } \\
\hline
\end{tabular}

* Les écartements de plantation sont de 3,5 m entre les lignes et de $2 \mathrm{~m}$ sur les lignes, soit une densité de plantation de 1429 plants/ha.

dans la proportion de 2/3-1/3. Pour dix des espèces étudiées, la moitié des pots de pépinière a été remplie avec ce substrat stérilisé au Maposol (matière active : méthamsodium aujourd'hui interdit en Europe ${ }^{1}$ ) afin de déceler, par comparaison avec le substrat non traité, d'éventuelles infections des jeunes plants dues aux microorganismes présents dans la terre et le terreau utilisés. Ces infections peuvent soit avoir un effet positif avec l'installation de symbioses, soit un effet négatif avec la présence de pathogènes.

Après le prétraitement, les graines ont été semées directement dans les pots à raison de deux graines par

\footnotetext{
${ }^{1}$ https://www.anses.fr/fr/content/produits-à-base-de-métam-sodium$\underline{\text { l’anses-annonce-le-retrait-des-autorisations-de-mise-sur-le }}$
}

pot. Seul Anogeissus leïocarpa, en raison de la petite taille de ses graines et de leur faible pouvoir germinatif (entre 1 et $2 \%$ ), a été semé en germoir et repiqué en pots au fur et à mesure des germinations au stade quatre feuilles.

Les semis ont été faits sous une ombrière en toile plastique perforée créant un ombrage de $50 \%$. Cette ombrière, que l'on retire généralement 3 à 4 semaines après la germination, est restée en place plus longtemps en raison de l'étalement des récoltes de graines (tableau I), donc des semis et des germinations.

Pour toutes les espèces, les pots ont été déplacés tous les 15 jours, ce qui a permis d'éliminer les pots vides et de classer les plants en fonction de leur taille. Cette opération a pour effet de sectionner les racines (cernage) sortant des pots. Les espèces de zones sèche développent 
très rapidement un pivot qui s'enfonce dans le sol en passant par les trous de drainage. Couper ces racines, en déplaçant régulièrement les pots, induit l'initiation de nouvelles racines et un chevelu racinaire dense qui maintient la motte pendant le transport des plants et la plantation. À la sortie de pépinière, les plants ont un bon équilibre entre les parties aérienne et racinaire, ce qui contribue à augmenter le taux de reprise à la plantation, surtout pour les espèces sensibles à un arrêt des pluies de plusieurs jours qui suivrait la plantation.

Les traitements phytosanitaires ont été réduits au maximum : un seul traitement fongicide a été appliqué pour prévenir les fontes de semis ainsi qu'une seule pulvérisation localisée d'insecticide pour lutter contre les criquets s'attaquant à Faidherbia albida. Des appâts empoisonnés ont été utilisés contre des petits rongeurs qui déterraient des graines.

Parmi les 22 espèces élevées en pépinière, seulement 12 ont pu être plantées avec le nombre de plants initialement prévu (224). Pour les autres espèces, il n'y a pas eu assez de graines, certaines ont posé des problèmes de germination, notamment Balanites sp. et Spondias mombin qui ont été multipliées par bouturage.

Certaines récoltes de graines ont été tardives (tableau I) ; ces espèces n'ont été élevées que pendant 75 à 90 jours, voire moins, au lieu des 4 à 5 mois normalement nécessaires pour un bon aoûtage et la lignification de la tige. Les plants étaient petits à la plantation (photo 2).

\section{Plantation}

Après abattage et dessouchage des arbres présents dans les champs abandonnés, le sol a été travaillé le 10 mai 1990 avec un pulvériseur lourd à disques. La trouaison manuelle de $40 \times 40 \times 40 \mathrm{~cm}$ a été faite entre le 28 mai et le 9 juin.

Une fertilisation PK (mélange de $40 \mathrm{~g}$ de chlorure de potasse, $70 \mathrm{~g}$ de phosphate tricalcique et $170 \mathrm{~g}$ de dolomie par plant) sur la moitié des plants a été apportée au fond du trou de plantation les 8 et 9 juin 1990 avant rebouchage. La plantation a été réalisée les 14 et 15 juin 1990, au début de la saison des pluies après un cumul pluviomé-
Tableau II.

Prétraitements et germination des semences utilisées. Pre-treatment and germination of the seeds used.

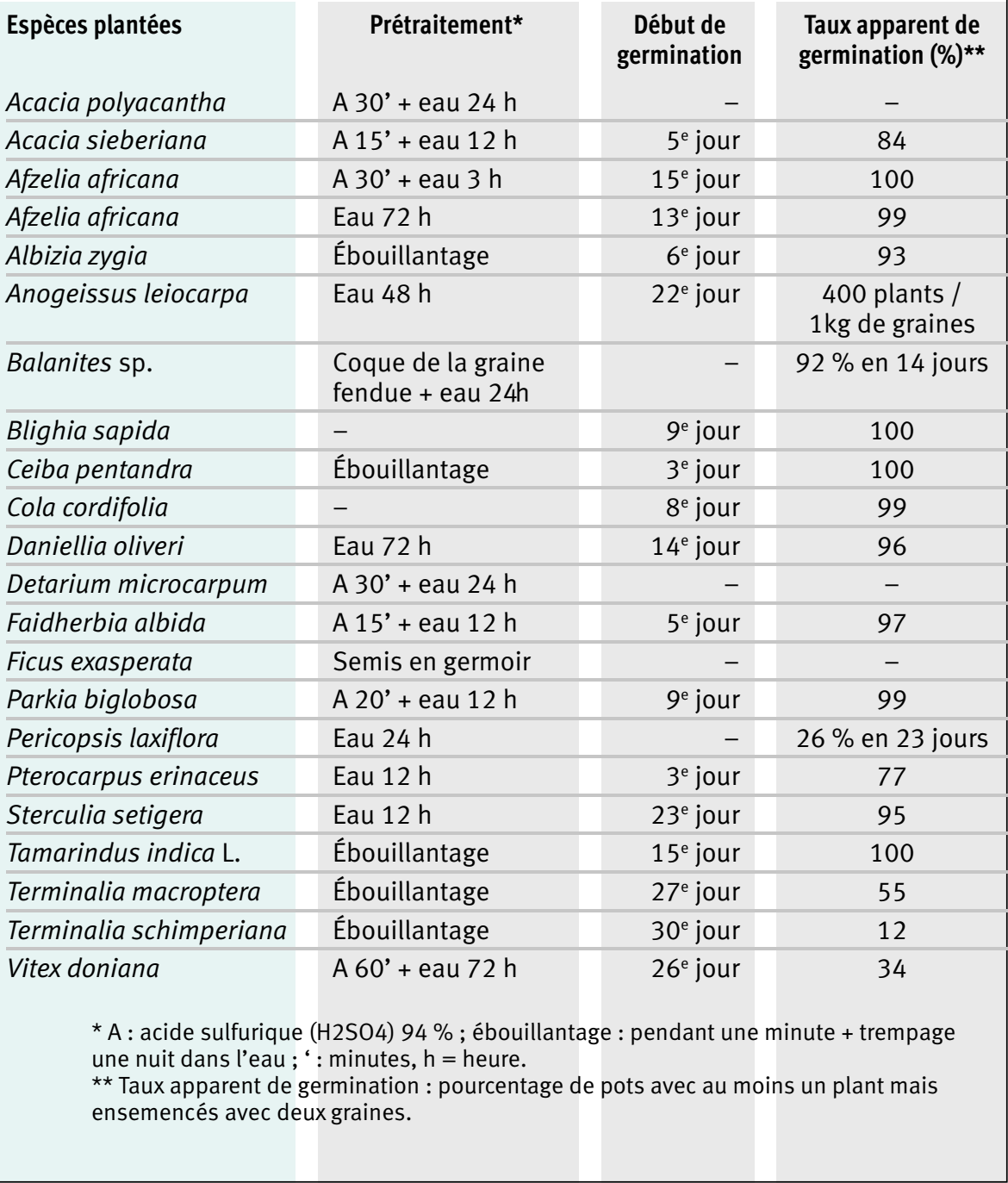

trique de $89,5 \mathrm{~mm}$ depuis le début du mois et une pluie de $12,5 \mathrm{~mm}$ le 14 juin. Lors de la plantation, la base des pots a été sectionnée à 1-2 cm afin d'éliminer les chignons racinaires de fond de pot qui se forment habituellement dans le type de conteneurs utilisés. Les pots ont été aussi fendus sur toute leur longueur pour sectionner les racines qui se sont enroulées le long des parois. Ces chignons et enroulements, lorsque les racines grossissent, peuvent finir plusieurs années plus tard par étrangler le système racinaire et provoquer la mort des plants ou favoriser les chablis.

Comme les planteurs maîtrisaient bien la technique de plantation, aucun remplacement n'a été nécessaire.

Aucune attaque de termites n'a été à déplorer alors que cet insecte est souvent craint, sans raison, par les sylviculteurs dont certains utilisent préventivement des insecticides à la plantation. 


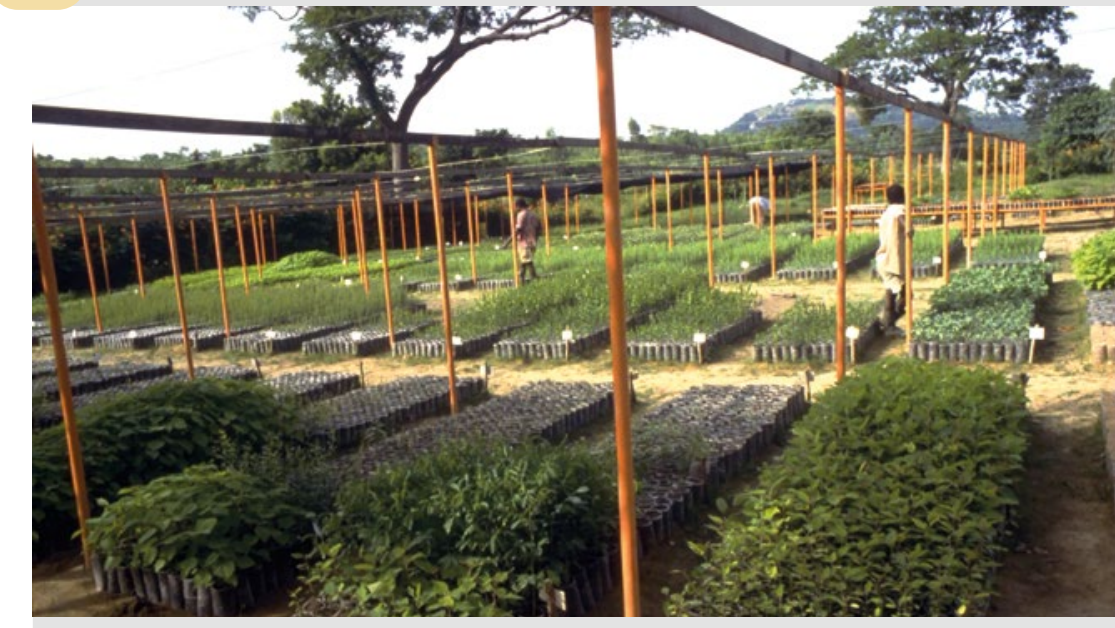

Photo 2.

La pépinière de Lataha, fin mai 1990. Les ombrières ont été retirées pour endurcir les plants avant la plantation. On note la présence de pots vides et des différences dans la taille des plants d'une même espèce. Ces différences résultent de prétraitements des graines non satisfaisants qui ont entraîné l'étalement des germinations, voire une absence de germination. The Lataha nursery, end of May 1990. The shades have been removed to harden the plants before planting. Empty pots and differences in the size of plants of the same species were noted. These differences are the result of unsatisfactory pre-treatment of the seeds, which led to spreading of germination or even a lack of germination.

Photo D. Louppe.

miner la végétation ligneuse et les lianes indésirables. Il est toujours autorisé en $2020^{2}$. Dans l'ensemble de l'arboretum, les drageons des autres espèces ligneuses, bien que beaucoup plus rares, ont été aussi détruits de la même manière.

Après deux années de croissance, les plants de Faidherbia albida ont été attaqués par des rongeurs, probablement des rats de Gambie, qui ont creusé le sol pour aller manger les racines. Quatre-vingt-quatorze plants sur 224 ont dû être ainsi remplacés. Les plants touchés étaient ceux les plus proches du refuge que procurait l'andain (regroupement des troncs des arbres abattus afin de libérer le terrain) à ces rongeurs qui ne se sont pas attaqués aux autres espèces.

\section{Méthode expérimentale}

Un arboretum n'a pas pour objectif de comparer des espèces qui n'ont aucun lien commun, notamment en raison de leur morphologie, de leurs utilisations et qualités de bois différentes, et de leurs usages autres que le bois. Son objectif est de tester le comportement des espèces en plantation afin de déterminer celles qui pourront être utilisées soit en plantations pures, soit dans des systèmes agroforestiers, voire en ornemental, sans préjuger de leurs usages potentiels : bois d'œuvre, protection des sols, production de fruits, de four-

\section{Entretiens}

En première année, trois entretiens ont été réalisés : désherbage manuel en juin, désherbage mixte avec sarclage manuel sur la ligne suivi d'un passage de pulvériseur à disques entre les lignes à la fin août et fin octobre - début novembre. En deuxième année, trois entretiens mixtes ont été réalisés en juin, août et novembre, puis deux en année 3. Les arbres ayant une croissance lente, un passage de pulvériseur à disques a été réalisé entre les lignes en fin de saison des pluies pour réduire les risques de feu. Cet entretien s'est fait jusqu'en 1999 dans les parcelles où il s'avérait nécessaire. Des pare-feu ont été entretenus tous les ans en périphérie de l'ensemble des plantations expérimentales.

\section{Problèmes rencontrés}

Le passage du pulvériseur à disques après défrichement du terrain a provoqué, en découpant les racines superficielles, une apparition massive de drageons, essentiellement chez Daniellia oliveri. En mars 1991, il était devenu difficile de séparer visuellement les plants de cette espèce issus de pépinière de ceux issus de drageons. Il fallait donc éliminer ces derniers pour éviter de perturber l'expérimentation car, en majorité, leur croissance était plus rapide que celle des plants de pépinière. En avril 1991, les drageons ont été coupés au sécateur au niveau du sol et du Garlon déposé immédiatement sur la section avec un pinceau afin de faire mourir la souche. Le Garlon est un herbicide systémique produit par Dow AgroSciences composé de Triclopyr ( $240 \mathrm{~g} / \mathrm{l})$ et d’Aminopyralide (30 g/l). Il est utilisé pour élirage, de fibres, etc. Dans la majorité des cas, les arboretums sont composés de petites parcelles de quelques plants, ce qui ne permet pas de réellement évaluer leur comportement en plantations monospécifiques ni d'établir des courbes de croissance fiables. Au contraire, l'arboretum installé dans le cadre de ce projet a été conçu pour y mener une sylviculture classique et conduire chaque espèce jusqu'au terme de la révolution et l'exploitation finale. Le protocole initial avait prévu des éclaircies dont le rythme serait fonction de la vitesse de croissance de chaque espèce. In fine, 10 à 16 arbres par parcelle, les meilleurs, tant en forme qu'en croissance, devaient rester en fin de révolution. Un autre objectif visait à récolter des semences sur les arbres sélectionnés par les éclaircies en vue de futures plantations. Pour ce faire, les parcelles devaient toutes être de grande taille. Toutes devaient compter 224 plants, soit 8 lignes de 28 plants à écartement de 2,0 x 3,5 m pour une superficie de $1596 \mathrm{~m}^{2}$. Cependant, comme 10 espèces ont posé des problèmes en pépinière (tableaux I et II), celles-ci n'ont pas pu être produites en quantités suffisantes et ont été plantées sur des parcelles plus petites mais aussi grandes que possible, de superficie variable selon le nombre de plants disponibles. Ainsi, seules 12 espèces sur 22 ont pu être plantées en parcelles complètes.

En 1990, outre le comportement des espèces en plantations, d'autres questions se posaient, questions pour lesquelles nous souhaitions avoir un début de réponse avant d'installer des dispositifs statistiques plus précis si cela

${ }^{2}$ https://ephy.anses.fr/ppp/garlon-excel. 
s'avérait nécessaire au vu des premières investigations. À cette époque, l'inoculation avec des rhizobiums et des mycorhizes avait déjà fait l'objet de nombreuses études, synthétisées par Brunck et al. (1990). Leur effet bénéfique pouvait-il être annihilé par des organismes pathogènes comme les nématodes?

L'importance du rôle des microorganismes du sol nous questionnait donc.

A-t-on avantage à stériliser les sols de pépinière ? Pour répondre à cette question, un test avec huit espèces a été mis en place. La moitié des plants de chaque espèce ont été éduqués sur un sol stérilisé au préalable (Maposol), l'autre moitié sur un sol n'ayant reçu aucun traitement. L'objectif était de comparer des plants dont les racines se sont développées dans un milieu stérilisé au préalable à ceux élevés sur un sol ayant conservé toute sa microfaune et flore. Une meilleure croissance des plants était attendue sur un sol sans pathogènes, nématodes et champignons a priori nuisibles. De meilleures conditions de démarrage en plantation étaient aussi espérées.

Les nématodes sont des pathogènes particulièrement redoutés. Déjà, en 1961, Michel et Vilardebo signalaient que plusieurs espèces de nématodes s'attaquaient chacune à de nombreuses espèces de différents genres et familles de plantes cultivées et leur occasionnaient des dégâts se traduisant par de fortes pertes de production. Fortuner et Couturier (1983) avaient observé que diverses espèces d'arbres de la forêt naturelle de Côte d'Ivoire pouvaient être des hôtes de nématodes parasites des cultures, ce qui pourrait poser des problèmes dans les systèmes agroforestiers. En 1985, Germani et al. avaient montré que les attaques de nématodes sur arachide réduisaient fortement la nodulation bactérienne et faisaient baisser la mycorhization, entraînant une diminution de l'assimilation du phosphore et une moindre résistance de la plante à la sécheresse. Cela aurait aussi pu concerner certaines espèces d'arbres et réduire leur croissance. Quelques années plus tôt, Alexandre (1977) émettait l'hypothèse que l'absence de régénérations d'avodiré (Turraeanthus africanus (Welw. ex C.DC.) Pellegr.) sous les arbres mères était dues en partie à de fortes attaques de nématodes dont les racines de l'arbre mère sont infectées. Au moment de la mise en place du dispositif, la question était de savoir si les nématodes attaquent les jeunes plants en pépinière et limitent leur développement sur le terrain.

Cependant, avec un seul traitement de stérilisation du sol, il est impossible de quantifier la part de l'effet des nématodes et de celui des bactéries ou des champignons. En dehors des fontes de semis, les champignons peuvent soit former des mycorhizes et être utiles à la plante, soit être pathogènes et la détruire. Est-il utile ou non d'éliminer l'ensemble des champignons avant de semer les graines ? Les observations faites sur des graines traitées à l'acide sulfurique concentré puis semées sur sol stérilisé à la chaleur ont montré qu'un réticule fongique se développait rapidement sur la graine et aux alentours. Cela laissait supposer que le champignon était déjà dans la graine sous la cuticule qui l'a protégé de l'acide (Stembert, 1991). Ce champignon, possiblement mycorhizien, ne serait donc pas impacté par la stérilisation du sol et, si c'est le cas, donnerait un avantage au sol stérilisé.

L'objectif recherché était de dégrossir l'effet global de la stérilisation du sol sur les jeunes plants sans entrer dans les détails comme l'identification des nématodes et des champignons, ou leurs modes d'action, ce qui aurait demandé des moyens dont nous ne disposions pas. La stérilisation du sol a été faite avec du Maposol (Métham sodium) en fumigation en confinement sous une bâche pendant une semaine. Ce biocide à la fois pesticide, herbicide et fongicide dont l'utilisation est complexe à mettre en œuvre en toute sécurité, en raison de sa très forte toxicité, est interdit en Europe.

\section{La fertilisation starter apporte-t-elle un avantage aux jeunes plants?}

Une fertilisation starter permet-elle d'accélérer la croissance des jeunes arbres et de fermer rapidement le couvert? L'élimination précoce de la concurrence herbacée par un couvert dense réduit le coût des entretiens. La fertilisation starter a consisté en un apport, au fond du trou de plantation, six jours avant celle-ci, de $40 \mathrm{~g}$ par plant de chlorure de potasse (60\% de $\mathrm{K}_{2} \mathrm{O}$ ), 70 g par plant de phosphate tricalcique ( $46 \%$ de $\mathrm{P}_{2} \mathrm{O}_{5}$ ) et $170 \mathrm{~g}$ par plant de dolomie ( $28 \%$ de $\mathrm{CaO}$ et $18 \%$ de $\mathrm{MgO}$ ). Il n'y a pas eu d'apport d'azote pour ne pas réduire l'activité fixatrice des Rhizobium des légumineuses. L'hypothèse était que les plants ayant créé une symbiose en pépinière, car élevés sur un sol contenant du terreau forestier non stérilisé, pourraient avoir une meilleure croissance en plantation que ceux élevés sur sol stérilisé. Ces derniers n'auraient été infectés qu'après plantation par les rhizobiums présents dans le sol agricole en place, vraisemblablement moins riche et moins divers en rhizobiums qu'un terreau forestier. Les plants infectés plus précocement étaient supposés avoir une fixation symbiotique de l'azote plus efficace qui améliorerait l'effet de la fertilisation starter sur la vitesse de croissance. Cet effet devrait également se ressentir sur les plants non fertilisés.

Dans l'arboretum, les parcelles de huit espèces (Acacia sieberiana, Albizzia zygia, Ceiba pentandra, Daniellia oliveri, Faidherbia albida, Sterculia setigera, Tamarindus indica, Terminalia macroptera) ont été divisées en quatre sous-parcelles :

- T1, sans engrais à la plantation - pépinière sur sol classique ;

- T2, sans engrais - pépinière sur sol stérilisé au Maposol ;

- T3, fertilisation starter à la plantation - pépinière classique ;

- T4, fertilisation starter - pépinière sur sol stérilisé.

Pour toutes les autres espèces, les parcelles n'ont été divisées qu'en deux : avec ou sans fertilisation starter.

\section{Analyses statistiques}

Cet arboretum ne présente pas de répétition. De ce fait, pour les comparaisons de moyennes deux à deux, nous avons utilisé le test de Student et pour la comparaison de plusieurs moyennes l'analyse de variance à un critère de classification au risque $\alpha=5 \%$. 


\section{Résultats et discussion}

\section{Résultats des trois premières années}

\section{Prétraitement des semences}

Les prétraitements utilisés pour accélérer la germination des graines (tableau II) - encore au stade expérimental pour de nombreuses espèces en 1989, mais affinés depuis (Louppe et al., 1992 ; Willan, 1992 ; CNSF, 2012 ; Sanogo, 2015) - n’ont pas tous donné les résultats escomptés faute de connaissances suffisantes. Un prétraitement adéquat aurait dû favoriser une germination groupée (sortie de l'apex racinaire de la graine) en moins de 10 jours.

Le taux de germination est relativement bas pour les deux Terminalia et Vitex doniana dont les graines ont en partie pourri au lieu de germer. Même si des progrès sur la conservation des graines et leur traitement avant semis ont été réalisés, les recherches sur ce sujet nécessitent d'être poursuivies.

\section{Stérilisation du substrat de pépinière}

La comparaison de sols stérilisés ou non a été menée sur 30 espèces différentes tant exotiques que locales. Parmi ces 30 espèces, 10 ont été plantées dans l'arboretum. Les espèces dont les graines ont été récoltées après mars 1990 n’ont pu être intégrées à cette étude. Les mesures faites entre le $42^{\mathrm{e}}$ et le $57^{\mathrm{e}}$ jour après le semis, pour les 10 espèces, sont présentées au tableau III.
Seules Daniellia oliveri et Faidherbia albida montrent un effet positif significatif de la stérilisation du substrat, laquelle a un effet négatif très fort sur la croissance d'Acacia polyacantha. Pour les autres espèces, l'effet n'est pas détectable statistiquement. Sur les trente espèces testées, quatorze ont réagi à la stérilisation du sol, huit avec une croissance plus importante et six avec une diminution de croissance (Louppe et al., 1991). On pourrait approfondir l'étude pour déterminer les causes de la réponse. On pourrait en effet penser que la stérilisation du sol empêche la symbiose rhizobienne d'où une moindre croissance d'Acacia polyacantha ; si c'était le cas, Faidherbia albida aurait dû réagir de la même manière. Or c'est le contraire qui a été observé ! Quoi qu'il en soit, la stérilisation des sols en pépinière ne présente pas suffisamment d'intérêt par rapport aux risques sanitaires pour les pépiniéristes. Cette technique ne sera pas conseillée d'autant que la manipulation d'un biocide nécessite un savoir-faire et un équipement de protection sophistiqué pour éviter toute contamination.

L'effet de ce traitement en pépinière a néanmoins été mesuré en plantation (tableaux IV et V). Le tableau IV résume l'effet conjugué de la stérilisation du sol en pépinière et de la fertilisation starter. En raison de la forte hétérogénéité des sols, notamment la présence inévitable de termitières (photo 1), les comparaisons statistiques ne mettent pas en évidence de différences significatives. Il aurait fallu, pour cela, avoir un dispositif en blocs avec trois répétitions au minimum. Néanmoins, certaines tendances semblent se dégager :

\section{Tableau III.}

Comparaison de la croissance en pépinière de dix espèces locales en fonction de la stérilisation ou non du sol (hauteurs en $\mathrm{cm}$ ).

Comparison of nursery growth of ten local species in relation to soil sterilisation or not (heights in $\mathrm{cm}$ ).

\begin{tabular}{|c|c|c|c|c|c|}
\hline Espèces & $\begin{array}{l}\hat{A ̂ g e}^{*} \\
\text { (jours) }\end{array}$ & $\begin{array}{l}\text { Sol non } \\
\text { stérilisé }\end{array}$ & $\begin{array}{c}\text { Sol } \\
\text { stérilisé }\end{array}$ & $\begin{array}{l}\text { Différences } \\
(\%)^{\star \star}\end{array}$ & $\begin{array}{l}\text { Signification } \\
\text { statistique }\end{array}$ \\
\hline Acacia polyacantha & 57 & 39,6 & 32,7 & $-17,6$ & THS \\
\hline Acacia sieberiana & 55 & 35,9 & 37,4 & $+4,1$ & NS \\
\hline Albizzia zygia & 56 & 6,9 & 6,5 & $-5,5$ & NS \\
\hline Ceiba pentandra & 42 & 20,8 & 20,2 & $-2,7$ & NS \\
\hline Daniellia oliveri & 57 & 11,9 & 14,0 & $+18,4$ & THS \\
\hline Detarium microcarpum & 57 & 9,9 & 9,8 & $-0,4$ & NS \\
\hline Faidherbia albida & 55 & 33,0 & 35,4 & $+7,2$ & $\mathrm{~S}$ \\
\hline Sterculia setigera & 54 & 18,5 & 19,8 & $+6,5$ & NS \\
\hline Tamarindus indica & 56 & 19,7 & 19,0 & $-3,5$ & NS \\
\hline Terminalia macroptera & 55 & 4,0 & 4,4 & $+10,0$ & NS \\
\hline
\end{tabular}

- la stérilisation du sol en pépinière semble avoir un effet positif alors que la fertilisation n'en a pas (ou dont l'effet engrais semble inférieur à la variabilité de la fertilité du sol) pour Acacia polyacantha, Afzelia africana et Albizia zygia ;

- la stérilisation du sol ne semble pas avoir d'effet ou d'effet négatif marqué sur les autres espèces ;

- la fertilisation starter semblerait avoir un effet sur la croissance de Ceiba pentandra élevé sur sol stérilisé et sur Sterculia setigera élevé sur sol non stérilisé ;

- la fertilisation starter semble avoir amélioré la croissance de Detarium microcarpum, Vitex doniana, bien que leur croissance soit très faible, et Ficus exasperata.

L'évolution de l'effet de la stérilisation du sol de pépinière a été étudiée en plantation jusqu'à 2,5 ans, indépendamment de la fertilisation puisque son effet est en grande partie masqué par la variabilité des sols. Les résultats sont présentés dans le tableau V. 
Tableau IV.

Croissance en plantation de plants élevés en pépinière sur sol stérilisé ou non et fertilisés ou non à la plantation (mesures à 20 mois).

Plantation growth of nursery raised plants on sterilised or unsterilised soil and fertilised or unfertilised at planting (measurements at 20 months).

Arboretum 90-01 : mesures à 20 mois

Espèces

Effet stérilisation (\%)

Acacia sieberiana

Effet stérilisation (\%)

Afzelia africana

Effet stérilisation (\%)

Albizia zygia

Effet stérilisation (\%)

Anogeissus leiocarpa*

Balanites sp.

Blighia sapida

Effet stérilisation (\%)

Ceiba pentandra

Effet stérilisation (\%)

Cola cordifolia

Effet stérilisation (\%)

Daniellia oliveri

Effet stérilisation (\%)

Detarium microcarpum

Faidherbia albida

Effet stérilisation (\%)

Ficus exasperata

Parkia biglobosa

Effet stérilisation (\%)

Pericopsis laxiflora*

Pterocarpus erinaceus*

Spondias mombin

Sterculia setigera

Effet stérilisation (\%)

Tamarindus indica

Effet stérilisation (\%)

Terminalia schimperiana

Terminalia macroptera*

Vitex doniana
Sol de pépinière**
Sans engrais

\section{S (\%)}

$0 \quad 100$

1

100

0,0

98
100

2,0

2,0
86

86

0,0

90

90

8,9

82

57
98

98

$-5,1$

$-10,0$

98

0,0

93

100

7,5

51

48
-59

20
98

91

$-7,1$

100

91

89

$-2,2$

42

69

32

100

96
$-4,0$

$-4,0$

100

98

$-2,0$

100
73

73
95
$98 \quad 245$
H (cm)

215

238
10,7

148

155

4,7

39
50

28,2

120

151

131

78

120

108

245

$-2,9$

$-2,9$
81

93

14,8

18

22

22,2

12

89

85

$-4,5$

99

62
56

56
$-9,7$

$-9,7$
14

57

106

157

160

1,9

120

120

0,0
133

133

48

Avec fertilisation starter

D (mm) S (\%)

$\begin{array}{rr}66 & 98 \\ 72 & 100\end{array}$

$72 \quad 100$

9,1

$27 \quad 100$

28

3,7

13

17

30,8

29

33
13,8

42

16

16
27

27

0,0

$-9,2$

$\begin{array}{rr}67 & 96 \\ 64 & 100\end{array}$

$-4,5$

43

$43 \quad 100$

$2,3-7,0$

$4 \quad 57$

$\begin{array}{lll}4 & 63 & 24\end{array}$

0,0

3

18

18

$-16,7$

28

19

5,6

10,5

\begin{tabular}{r|r}
11 & 17
\end{tabular}

$100 \quad 79$

$91 \quad 85$

$\begin{array}{rr}91 & 85 \\ -9,0 & 7,6\end{array}$

$\begin{array}{ll}7,6 & 0,0\end{array}$

\begin{tabular}{r|r}
79 & 68 \\
\hline
\end{tabular}

$84 \quad 65$

$6,3-4,4$

$\begin{array}{rr}6,3 & -4,4 \\ 14 & 12\end{array}$

\begin{tabular}{rr}
52 & 41 \\
\hline 6 & 244 \\
\hline
\end{tabular}

$100 \quad 179$

\begin{tabular}{ll}
100 & 179 \\
\hline 100 & 155
\end{tabular}

$\begin{array}{rr}100 & -13,4\end{array}$

$100-13,4-17,1$
$100-137$

\begin{tabular}{|r|r|r|}
100 & 137 & 42 \\
\hline 100 & 129 & 41 \\
\hline
\end{tabular}

\begin{tabular}{rrr}
100 & 129 & 41 \\
\hline 0,0 & $-5,8$ & $-2,4$
\end{tabular}

\begin{tabular}{|r|r|r}
0,0 & $-5,8$ & $-2,4$ \\
\hline 100 & 120 & 34
\end{tabular}

\begin{tabular}{|l|l|l|}
69 & 44 & 16 \\
\hline
\end{tabular}

\begin{tabular}{l|l|l}
81 & 52 & 27
\end{tabular}

27

18,2

14,2
7,5

7,5

$-9,8$

$-2,9$

* Plants de petite taille au départ ou abroutis par les herbivores, ce qui explique la sous-estimation des taux de survie par rapport aux mesures ultérieures.

$\star \star 0$ : sol non stérilisé en pépinière ; 1 : sol stérilisé en pépinière. 
Tableau V.

Croissance en plantation de plants élevés en pépinière sur sol stérilisé ou non (hauteurs en $\mathrm{cm}$ ).

Plantation growth of nursery grown plants on sterilised or unsterilised soil (heights in $\mathrm{cm}$ ).

\begin{tabular}{|c|c|c|c|c|c|c|c|}
\hline Âge & $7 m$ & & $20 m$ & & & 1 mois & \\
\hline Espèces & Non stérilisé & Stérilisé & Non stérilisé & Stérilisé & Non stérilisé & Stérilisé & $\Delta(\%)$ \\
\hline Acacia sieberiana & 62 & 70 & 155 & 170 & 227 & 252 & +11 \\
\hline Afzelia africana & 26 & 27 & 39 & 49 & 71 & 84 & +18 \\
\hline Albizia zygia & 51 & 60 & 124 & 149 & 204 & 229 & +12 \\
\hline Blighia sapida & 46 & 39 & 113 & 115 & 178 & 198 & +11 \\
\hline Ceiba pentandra & 126 & 139 & 250 & 252 & 335 & 337 & 0 \\
\hline Daniellia oliveri & 16 & 15 & 19 & 23 & 44 & 44 & 0 \\
\hline Faidherbia albida & 49 & 57 & 84 & 84 & 117 & * & - \\
\hline Parkia biglobosa & 20 & 21 & 65 & 61 & 125 & 114 & -9 \\
\hline Sterculia setigera & 95 & 94 & 168 & 158 & 219 & 217 & -1 \\
\hline Tamarindus indica & 50 & 49 & 129 & 125 & 166 & 160 & -4 \\
\hline
\end{tabular}

Tableau VI.

Croissance de 22 espèces soudano-guinéennes sur la station de Lataha (Korhogo) entre 4,5 et 8,5 ans. Growth of 22 Sudano-Guinean species in the Lataha station (Korhogo) between 4.5 and 8.5 years.

\begin{tabular}{|c|c|c|c|c|c|c|c|c|c|c|c|c|c|c|c|c|}
\hline \multirow{2}{*}{$\begin{array}{l}\text { Années des mesures et } \\
\text { âge des plantations } \\
\text { Espèces }\end{array}$} & \multirow[b]{2}{*}{$\begin{array}{c}S \\
(\%)\end{array}$} & \multicolumn{2}{|c|}{$\begin{array}{c}1995 \\
54 \text { mois }\end{array}$} & \multirow[b]{2}{*}{$\underset{\left(m^{2} / \mathrm{ha}\right)}{\mathbf{G}}$} & \multirow[b]{2}{*}{$\begin{array}{c}\text { S } \\
(\%)\end{array}$} & \multicolumn{2}{|c|}{$\begin{array}{c}1996 \\
66 \text { mois }\end{array}$} & \multirow[b]{2}{*}{$\underset{\left(m^{2} / h a\right)}{\mathbf{G}}$} & \multirow[b]{2}{*}{$\begin{array}{c}\text { S } \\
(\%)\end{array}$} & \multicolumn{2}{|c|}{$\begin{array}{c}1997 \\
78 \text { mois }\end{array}$} & \multirow[b]{2}{*}{$\underset{\left(m^{2} / h a\right)}{G}$} & \multirow[b]{2}{*}{$\begin{array}{c}S \\
(\%)\end{array}$} & \multicolumn{2}{|c|}{$\begin{array}{c}1999 \\
102 \text { mois }\end{array}$} & \multirow[b]{2}{*}{$\underset{\left(m^{2} / \mathrm{ha}\right)}{\mathbf{G}}$} \\
\hline & & $\begin{array}{c}\mathrm{H} \\
(\mathrm{cm})\end{array}$ & $\begin{array}{c}\mathrm{Cg} \\
(\mathrm{cm})\end{array}$ & & & $\begin{array}{c}\mathrm{H} \\
(\mathrm{cm})\end{array}$ & $\begin{array}{l}\mathrm{Cg} \\
(\mathrm{cm})\end{array}$ & & & $\begin{array}{c}\mathrm{H} \\
(\mathrm{cm})\end{array}$ & $\begin{array}{l}\mathrm{Cg} \\
(\mathrm{cm})\end{array}$ & & & $\underset{(\mathrm{cm})}{\mathrm{H}}$ & $\begin{array}{l}\mathrm{Cg} \\
(\mathrm{cm})\end{array}$ & \\
\hline Acacia polyacantha & 78,6 & 283 & 17 & 2,58 & 73,7 & 311 & 19,7 & 3,26 & 59,4 & 300 & 22 & 3,26 & 33,9 & 415 & 29,3 & 3,18 \\
\hline Acacia sieberiana & 2,9 & 376 & 16 & 2,7 & 94,6 & 405 & 18,8 &, 75 & 91,1 & 398 & 20,8 & 4,48 & 75,4 & 445 & 21,8 & 4,1 \\
\hline Afzelia africana & 87,1 & 164 & 9 & 0,8 & 87,1 & 211 & 12,4 & 1,06 & 62,9 & 241 & 15,3 & 1,68 & 81,2 & 315 & 18 & 2,52 \\
\hline Albizia zygia & 74,6 & 382 & 18 & 2,75 & 80,8 & 369 & 22,1 & 3,67 & 63,3 & 350 & 25,2 & 4,57 & 48,7 & 549 & 29,3 & 4,75 \\
\hline Anogeissus leiocarpa & 93,3 & 490 & 18 & 3,44 & 88,4 & 607 & 23,7 & 5,65 & 94,2 & 688 & 28,1 & 8,43 & 85,7 & 1085 & 33,7 & 10,8 \\
\hline Balanites aegyptiaca & & & & & 7,1 & 75 & - & - & 0 & - & - & - & 0 & - & - & \\
\hline Blighia sapida & 92,4 & 324 & 17 & 3,04 & 92,9 & 374 & 19,7 & 3,79 & 86,6 & 389 & 21,7 & 4,63 & 87,5 & 439 & 23,8 & 5,45 \\
\hline Ceiba pentandra & 96,9 & 436 & 31 & 10,59 & 96,9 & 448 & 28,9 & 9,23 & 94,2 & 465 & 32,6 & 11,4 & 72,8 & 503 & 35,7 & 10,53 \\
\hline Cola cordifolia & 98,2 & 206 & 13 & 1,89 & 96,4 & 217 & 15,1 & 2,34 & 92,9 & 238 & 16,7 & 2,94 & 95,5 & 244 & 18,5 & 3,63 \\
\hline Daniellia oliveri & 52,2 & 101 & 6 & 0,21 & 56,7 & 130 & 8,2 & 0,19 & 23,2 & 138 & 9,9 & 0,26 & 50,4 & 206 & 10,5 & 0,42 \\
\hline Detarium microcarpum & & & & & 36,2 & - & - & - & 33,9 & 88 & - & - & 50,9 & 100 & - & 0,04 \\
\hline Faidherbia albida & 93,3 & 155 & 11 & 1,12 & 92 & 167 & 15,8 & 1,09 & 92,9 & 161 & - & 1,33 & 76,8 & 187 & 21 & 1,46 \\
\hline Ficus exasperata & 91,7 & 202 & 9 & 0,84 & & & & & 89,3 & 228 & 7,8 & 0,61 & 0 & - & - & \\
\hline Parkia biglobosa & 83,5 & 249 & 12 & 1,73 & 85,7 & 286 & 13,9 & 1,64 & 83,2 & 321 & 15,6 & 2,29 & 79 & 364 & 18,6 & 2,86 \\
\hline Pericopsis laxiflora & 81,2 & 191 & 12 & 1,33 & 53,1 & 192 & 9,9 & 0,55 & 41,7 & 213 & 10,6 & 0,53 & 30,4 & 318 & 17,8 & 0,94 \\
\hline Pterocarpus erinaceus & 65,4 & 444 & 20 & 2,97 & 61,6 & 555 & 26,5 & 4,77 & 64,4 & 664 & 31,2 & 7,15 & 60,7 & 879 & 38,4 & 10,04 \\
\hline Spondias mombin & & & & & & & & & 26,9 & 296 & 26,2 & 2,1 & & & & \\
\hline Sterculia setigera & 99,1 & 339 & 19 & 4,07 & 98,7 & 376 & 20,9 & 4,85 & 98,7 & 396 & 25 & 7 & 97,3 & 424 & 23,3 & 5,93 \\
\hline Tamarindus indica & 97,8 & 253 & 14 & 2,18 & 96,9 & 286 & 15,7 & 2,65 & 97,3 & 283 & 18,8 & 3,89 & 96,4 & 296 & 18,4 & 3,64 \\
\hline Terminalia schimperiana & 100 & 429 & 20 & 4,55 & 100 & 534 & 23 & 6,01 & 100 & 504 & 25,2 & 7,22 & 100 & 634 & 28,6 & 9,13 \\
\hline Terminalia macroptera & & & & & 83 & 226 & 15,3 & 1,8 & 82,1 & 280 & 15,9 & 2,89 & 69,3 & 360 & 19,9 & 2,84 \\
\hline Vitex doniana & 62,5 & 123 & 6 & 2,06 & 25 & 83 & - & - & 84,5 & 150 & 7,5 & 0,55 & 86,9 & 171 & 14,4 & 1,04 \\
\hline
\end{tabular}

$\mathrm{S}$ : taux de survie ; $\mathrm{H}$ : hauteur moyenne ; $\mathrm{Gg}$ : circonférence de l'arbre de surface terrière moyenne ; $\mathrm{G}$ : surface terrière rapportée à l'hectare. 
Deux années et demie après la plantation, les comparaisons de moyennes n'ont toujours pas pu mettre en évidence de différences significatives en hauteur au seuil de $5 \%$. Quatre espèces semblent cependant montrer une meilleure croissance si les plants ont été élevés en pépinière sur sol stérilisé. Ces différences doivent être considérées avec circonspection car plusieurs des espèces testées ont été abrouties, à l'exemple de Afzelia africana. La présence de termitières, notamment les deux sur la parcelle de Blighia sapida, faussent certainement les résultats obtenus.

Ces résultats préliminaires laissent supposer qu'il pourrait y avoir des interactions, positives ou négatives, entre la stérilisation du sol et la fertilisation starter. Celles-ci pourraient être un sujet d'étude (Brunck et al., 1990).

\section{Taux de survie}

Dans l'ensemble, les taux de reprise à 54 mois (tableau $\mathrm{VI}$ ) sont satisfaisants et dépassent largement les $80 \%$. Quatre espèces échappent cependant à cette règle :

- Daniellia oliveri qui a végété, bien qu'ayant parfaitement réussi en pépinière, dès la plantation, et a commencé à dépérir au cours de la première saison sèche. La cause n'a pu en être déterminée. La difficulté rencontrée ensuite avec cette espèce est qu'elle drageonne abondamment (Bellefontaine, 2018), même à partir de racines d'arbres abattus. La parcelle a ainsi été très vite envahie par un grand nombre de drageons difficilement différenciables des arbres plantés dès qu'ils se trouvent sur la ligne de plantation.

- Terminalia macroptera montrait, deux heures après la plantation, un début de fanaison inquiétant. Le sectionnement du chignon racinaire de fond de pot au moment de la plantation a probablement détruit l'équilibre entre partie aérienne et partie souterraine, donc l'équilibre absorption d'eau/évapotranspiration. La reprise a néanmoins été bonne car les pluies sont arrivées rapidement. Un habillage du feuillage serait une précaution à prendre pour cette espèce.

- Pterocarpus erinaceus est une espèce très appétée et c'est vraisemblablement là qu'il faut trouver la cause de la mortalité observée, au contraire d'Afzelia africana qui, bien que très fortement broutée par les herbivores, a montré $87 \%$ de réussite.

- Detarium microcarpum est un cas particulier dont il sera question plus loin.

Pour les trois premières des quatre espèces ci-dessus, les variations des taux de survie (tableau $\mathrm{VI}$ ) au cours du temps sont certainement liées à l'abroutissement ${ }^{3}$. Ainsi, un arbre fortement brouté peut être compté comme mort une année et réapparaître l'année suivante sous la forme d'un rejet.

\footnotetext{
${ }^{3}$ Pendant les premières années de la station, espace protégé, les pasteurs transhumants coupaient les fils de fer barbelés pour y faire entrer le bétail afin qu'il s'alimente car, malgré les entretiens, la végétation herbacée était plus abondante qu'à l'extérieur qui était surpâturé. Certaines espèces d'arbres comme Afzelia africana,

Pterocarpus erinaceus, Khaya senegalensis fournissent par émondage un excellent fourrage de saison sèche et leurs jeunes plants, ainsi que ceux de quelques autres espèces, sont particulièrement appréciés par le bétail surtout quand il n'y a plus d'herbe à brouter.
}

\section{Floraison, fructification}

Dès la deuxième année, quelques plants d'Acacia polyacantha et de Sterculia setigera ont commencé à fleurir et à fructifier. En troisième année, la floraison a débuté chez Tamarindus indica et chez Blighia sapida dont un individu a fructifié abondamment.

\section{Résultats entre quatre et neuf ans}

Ces résultats sont présentés au tableau VI et illustrés par les planches photographiques 1 à 4 .

L'effet de la fertilisation starter n'ayant pas pu être mis en évidence, nous ne traiterons plus de ce sujet. En effet, comme on peut le voir sur les photos 1 et 4 , les variations locales de fertilité du sol dues aux termitières sont très importantes, davantage que les variations que l'on pourrait attribuer à la fertilisation.

Il faut souligner que, compte tenu de la forte densité de plantation, 1428 plants/ha, il convient de relativiser les taux de survie, d'autant que l'objectif à long terme

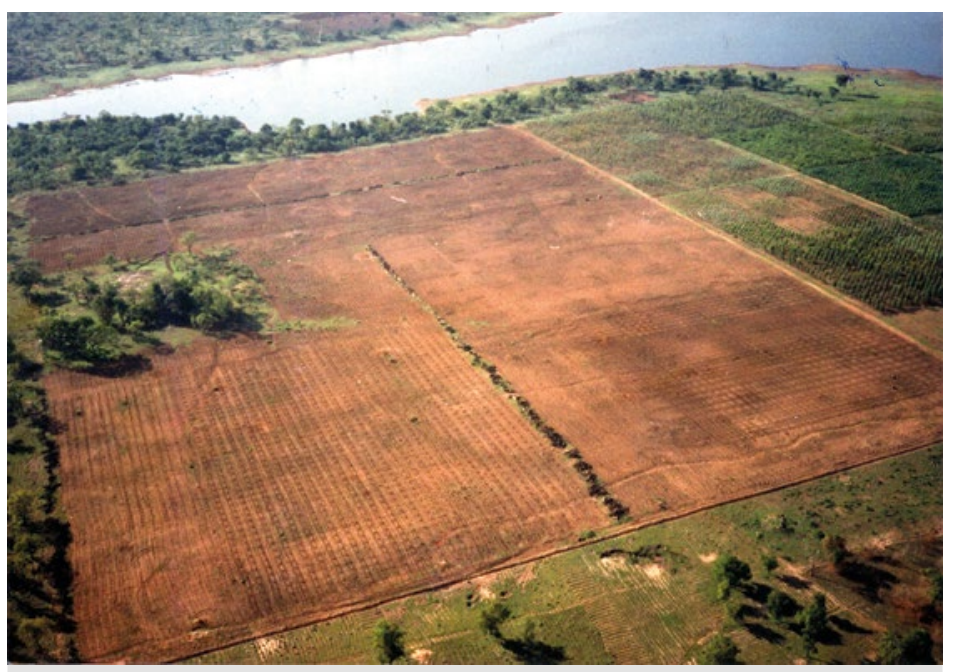

Photo 3.

Le terrain préparé destiné aux expérimentations de 1990. L'arboretum ne représente qu'une faible partie des plantations expérimentales installées en 1990. Le massif boisé que l'on aperçoit sur la gauche entoure le dôme granitique autour duquel sera installé l'arboretum. La faible quantité de bois dans les andains montre que le terrain était peu boisé, ce qui explique les ravines d'érosion liées aux activités agricoles antérieures. Ces ravines indiquent le sens des pentes. Toutes traces d'érosion ont disparu dans les deux à trois années qui ont suivi les plantations. Même les fortes pluies de 2019 qui ont entraîné une érosion sévère dans les terres agricoles voisines n'en ont pas causées dans les parcelles boisées. Sur la droite, on voit les plantations de 1988 et en bordure du lac de barrage une bande de forêt naturelle conservée quoique dégradée.

The land prepared for the 1990 experiments. The arboretum represents only a small part of the experimental plantations installed in 1990. The woodland seen on the left surrounds the granite dome around which the arboretum will be established. The small amount of wood in the windrows shows that the land was sparsely wooded, which explains the erosion gullies linked to previous agricultural activities. These gullies indicate the direction of the slopes. All traces of erosion disappeared within two to three years of planting. Even the heavy rains of 2019, which caused severe erosion in the neighbouring farmland, did not cause any erosion in the woodland plots. On the right are the plantations from 1988 and a strip of natural forest on the edge of the reservoir, which has been preserved but degraded. Photo taken in early June 1990.

Photo D. Louppe, début juin 1990. 

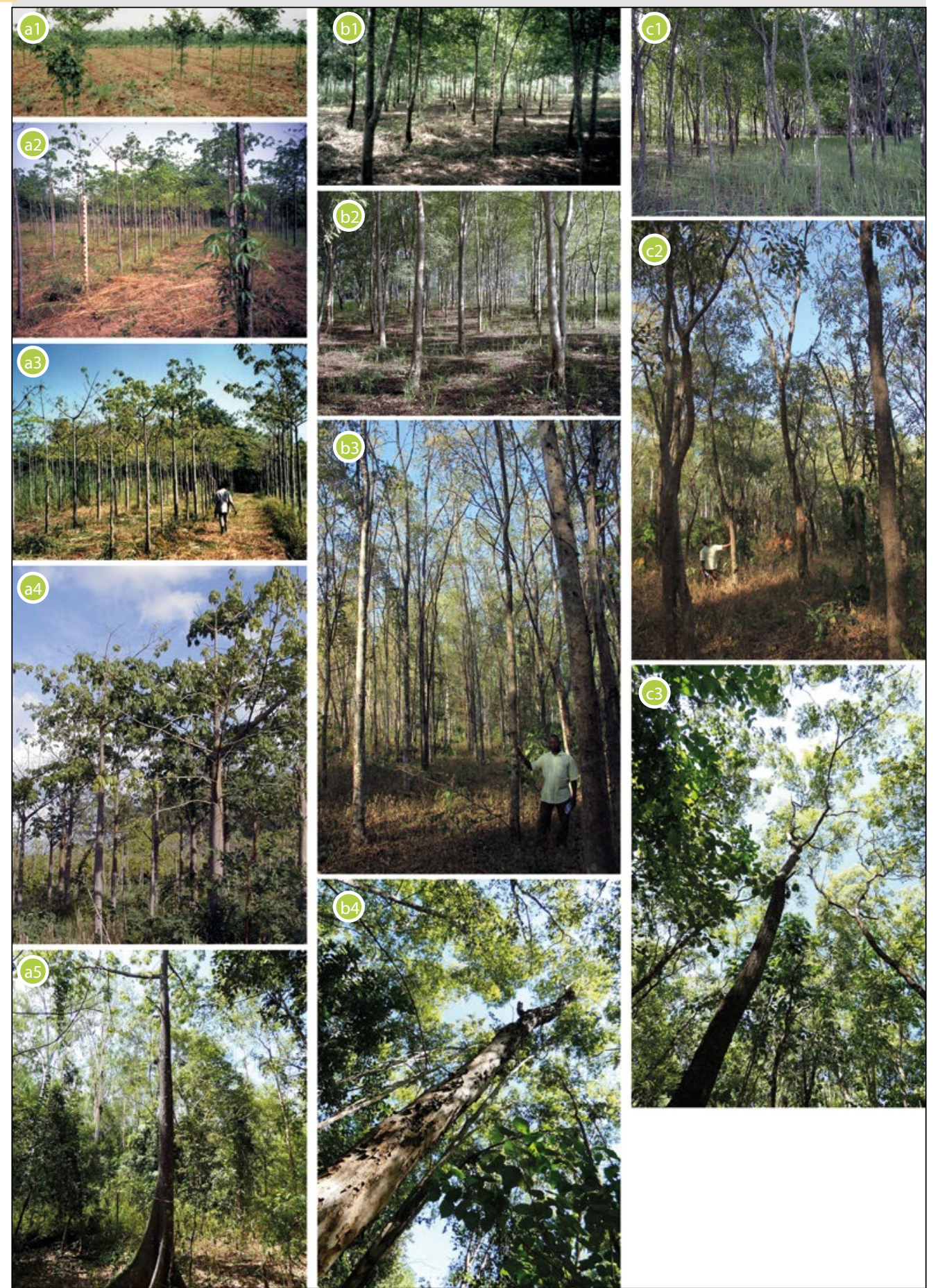

Planche photographique 1.

Ceiba pentandra : 15 mois (a1), 6 ans (a2), 9 ans (a3), 11 ans (a4) : les pieds les plus vigoureux sont sur une ancienne termitière mais on observe déjà les premiers dessèchements de cimes, et 29 ans (a5) : arbre isolé au milieu d'espèces spontanées. Anogeissus leiocarpa: 6 ans (b1), 11 ans (b2), 23 ans (b3) et 29 ans (b4). Pterocarpus erinaceus : 11 ans (c1), 23 ans (c2), 29 ans (c3). Ceiba pentandra: 15 months (a1), 6 years (a2), 9 years (a3), 11 years (a4): the most vigorous plants are on an old termite mound but the first drying up of the tops is already observed and 29 years (a5): isolated tree in the middle of spontaneous species Anogeissus leiocarpa: 6 years (b1), 11 years (b2), 23 years (b3) and 29 years (b4). Pterocarpus erinaceus: 11 years (c1), 23 years (c2), 29 years (c3). Photo D. Louppe. des plantations est d'obtenir une densité comprise entre 80 et 100 arbres adultes par hectare, soit seulement 5,6 à $7,0 \%$ des arbres plantés. À neuf ans, un taux de survie de $50 \%$ (112 arbres par parcelle) est donc plus qu'acceptable, ce qui est le cas de la majorité des espèces plantées à l'exception de :

- Balanites aegyptiaca ou " dattier du désert ", planté pour ses fruits, lequel a rapidement disparu car cette espèce des zones sahélienne et soudano-sahélienne a été plantée loin de son aire naturelle ;

- Ficus exasperata, espèce fourragère recherchée, à la limite nord de son aire d'extension, qui a végété jusqu'à 6 ans et demi pour finalement disparaître ;

- Spondias mombin, espèce fruitière que l'on trouve plutôt disséminée dans les terres cultivées, et qui ne semble pas adaptée aux plantations de type forestier ; sa plantation devrait se limiter à des individus isolés dans des vergers ou dans des jardins de case ;

- Acacia polyacantha qui, malgré une bonne reprise et une bonne croissance initiale (entre 190 et $230 \mathrm{~cm}$ de haut en 21 mois), montre une forte mortalité à partir de 5,5 ans : en 3 ans, il perd $55 \%$ de ses individus puis finit par disparaître. La cause probable de cet échec est une insuffisance d'alimentation en eau car il a été planté en dehors de ses sols de prédilection que sont les bas-fonds et la proximité des rivières (Arbonnier, 2019 ; Peltier, 1993). Cette espèce a montré une croissance juvénile spectaculaire sur une zone couverte de termitières (planche photos 4).

La mortalité importante observée chez Acacia sieberiana et Albizia zygia a sans doute des causes similaires. 


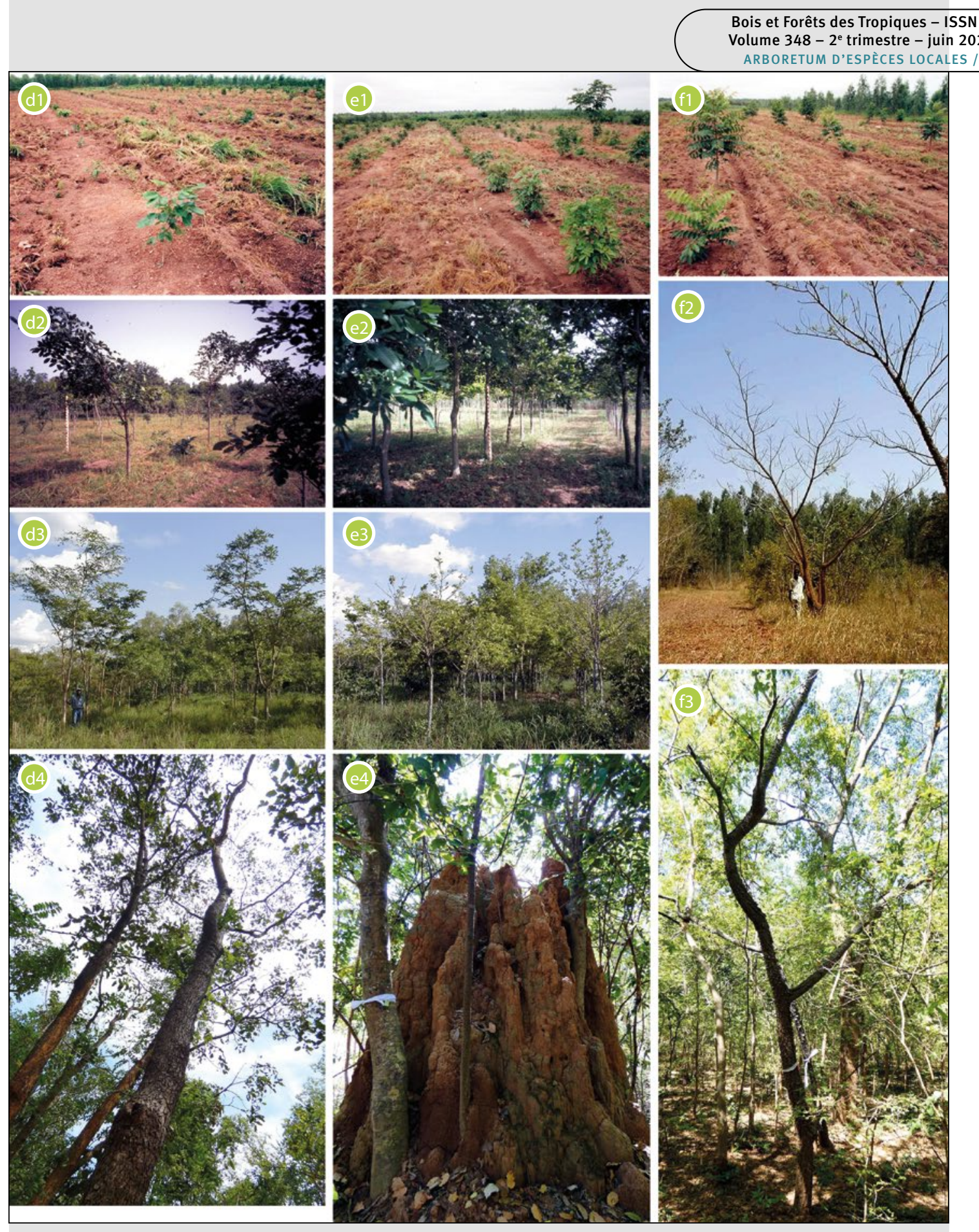

Planche photographique 2.

Afzelia africana : 15 mois (d1), 6 ans (d2), 11 ans (d3), 29 ans (d4). Blighia sapida: 15 mois (e1), 6 ans (e2) : les arbres de l'avant-plan sont sur une termitière et montrent une meilleure croissance et génèrent plus d'ombre au sol que ceux qui sont plus loin, 11 ans (e3) et 29 ans (e4) : l'espèce profite de la présence des termites qui, en retour, semblent profiter de la présence/protection des arbres et des déchets organiques qu'ils produisent. Spondias mombin : 15 mois (f1) : les plants issus de boutures d'arbres différents montrent une forte variabilité de croissance, 10 ans (f2) : quelques sujets sont bien développés mais la mortalité est néanmoins forte, 29 ans (f3) : le meilleur des quatre sujets survivant au milieu du recrû naturel d'espèces autochtones. Afzelia africana: 15 months (d1), 6 years (d2), 11 years (d3), 29 years (d4). Blighia sapida: 15 months (e1), 6 years (e2): the trees in the foreground are on a termite mound and show better growth and generate more shade on the ground than those further away, 11 years (e3) and 29 years (e4): the species benefits from the presence of termites which, in turn, seem to benefit from the presence/protection of the trees and the organic waste they produce. Spondias mombin: 15 months (f1): seedlings from cuttings of different trees show high variability in growth, 10 years (f2): some individuals are well developed but mortality is nevertheless high, 29 years (f3): the best of the 4 surviving individuals amidst the natural recrudescence of native species.

Photos D. Louppe. 

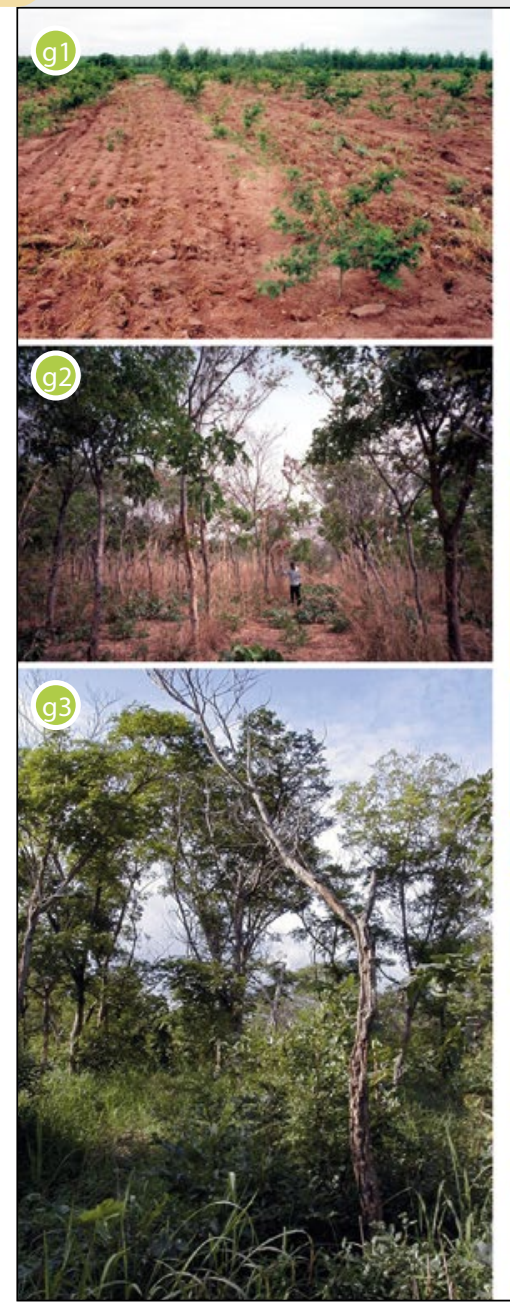
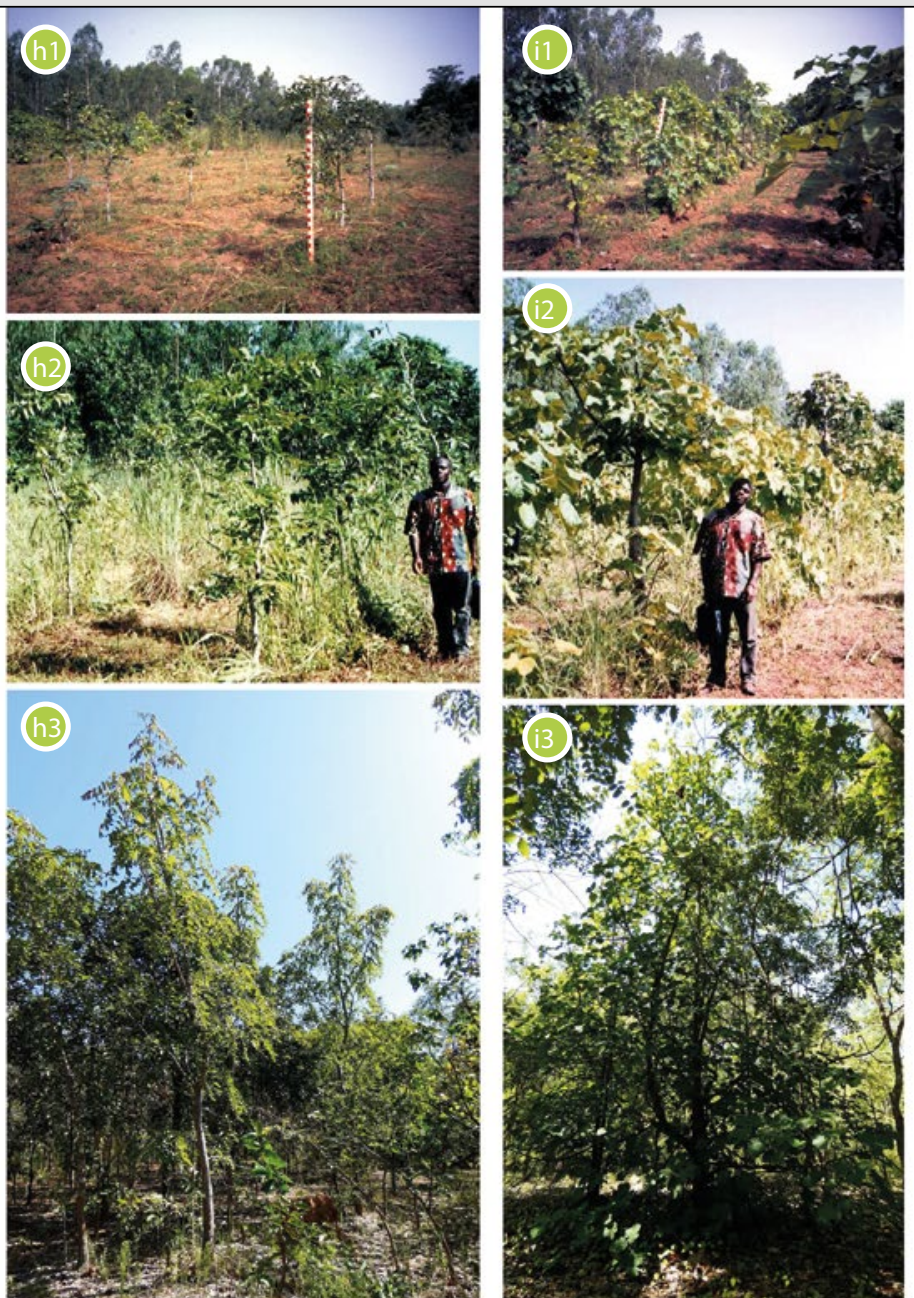
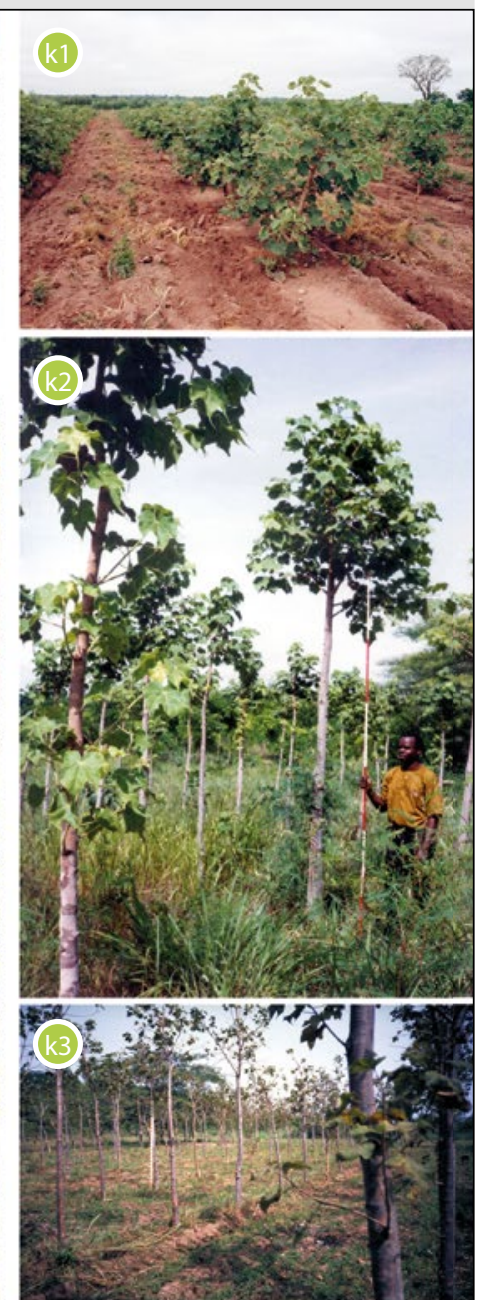

Planche photographique 3.

Albizia zygia: 15 mois (g1), 9 ans (g2) et 11 ans (g3), de nombreux arbres sont morts sur lesquels on a observé de nombreuses piqûres d'insectes. La question est de savoir si ce sont les insectes qui sont la cause de la mortalité ou si les insectes sont venus par ce que les arbres étaient affaiblis. Daniellia oliveri : 6 ans (h1), 8 ans (h2) et 29 ans (h3). Cola cordifolia: 6 ans (i1), 9 ans (i2) et 29 ans (i3). Sterculia setigera: 15 mois (k1), 4 ans ( $k 2)$ : les arbres ont été élagués, et 6 ans ( 33$)$.

Albizia zygia: 15 months (g1), 9 years (g2) and 11 years (g3) old, many trees have died and many insect bites have been observed. The question is whether the insects caused the mortality or whether the insects came through the weakened trees? Daniellia oliveri: 6 years ( $h 1)$, 8 years ( $h 2$ ) and 29 years ( $h 3$ ). Cola cordifolia: 6 years (i1), 9 years (i2) and 29 years (i3). Sterculia setigera: 15 months (k1), 4 years ( $k 2$ ): the trees have been pruned) and 6 years ( $k 3)$.

Photos D. Louppe.

Trois autres espèces ont un comportement qu'il convient d'expliquer ici.

Detarium microcarpum est une espèce dont la phase d'installation est particulièrement longue. Dès la première saison sèche, toutes les parties aériennes des plants se dessèchent puis tombent, donnant l'impression que le plant est mort. La saison des pluies suivante, une nouvelle pousse apparaît qui meurt en saison sèche et ainsi de suite pendant plusieurs années jusqu'à que la tige devienne persistante quand le système racinaire est suffisamment développé (Alexandre, 1993). Du fait de cette stratégie originale, le taux de survie apparent est de $0 \%$ jusqu'à 4,5 ans, mais de $50 \%$ quatre années plus tard.

Daniellia oliveri a une croissance particulièrement lente au départ. Le passage du pulvériseur à disques a provoqué un important drageonnage/bouturage des racines de Daniellia abattus dans cette parcelle. Ces rejets naturels ont été empoisonnés pour ne conserver que les individus plantés ; mais certains ont survécu. Les comptages et mesures ont donc été difficiles, expliquant les variations des taux de survie au cours du temps.

Chez Faidherbia albida, les racines d'un bon nombre de plants ont été mangées par des rongeurs avant la troisième saison sèche, obligeant à des remplacements trop tardifs pour que la reprise soit bonne. Bien que Faidherbia soit une espèce réputée fertilisante, elle est, dans le jeune âge, extrêmement sensible à la fertilité du sol, comme le montre sa croissance sur un transect traversant une termitière (tableau VII et photo 5 ). 


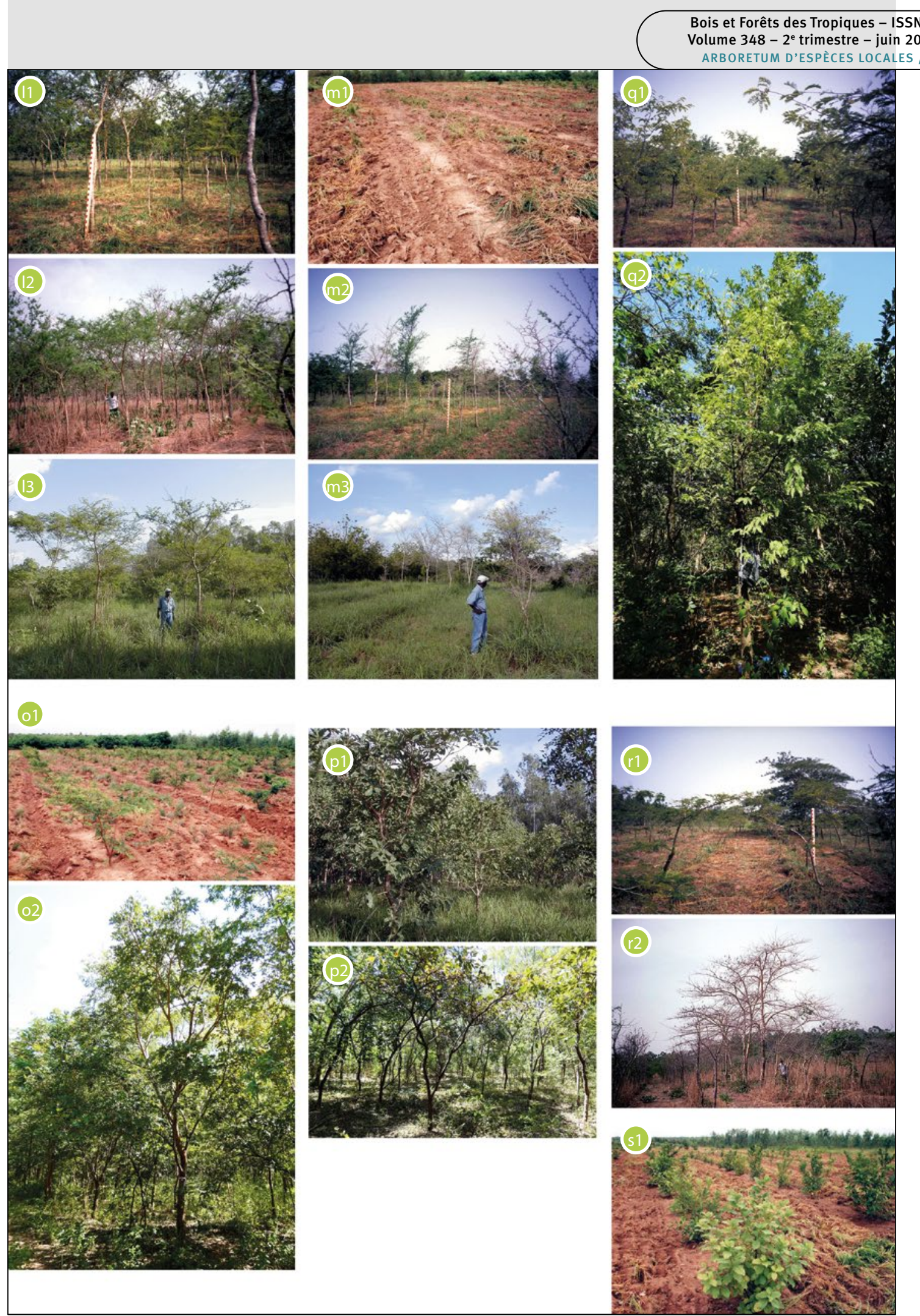

Planche photographique 4.

Acacia sieberiana: 6 ans (I1), 8 ans (I2), 11 ans (I3). Faidherbia albida: 15 mois (m1), 6 ans (m2) : les grands sujets sont sur une termitière), 11 ans (m3). Tamarindus indica: 6 ans (01), 29 ans (o2). Detarium microcarpum : 15 mois (p1), 29 ans (p2). Terminalia macroptera : 11 ans (q1), 29 ans (q2). Acacia polyacantha: 6 ans (r1), 8 ans $(r 2)$ : cette espèce montre une croissance exceptionnelle sur termitière uniquement. Ficus exasperata $: 1,5$ an (s1).

Acacia sieberiana: 6 years (11), 8 years (12), 11 years (13). Faidherbia albida: 15 months ( $m 1), 6$ years (m2): large trees are on a termite mound), 11 years ( $(m 3)$. Tamarindus indica: 6 years (o1), 29 years (o2).

Detarium microcarpum: 15 months ( $p 1), 29$ years ( $p 2)$. Terminalia macroptera: 11 years ( $q 1), 29$ years ( $q 2)$. Acacia polyacantha: 6 years ( $r 1)$, 8 years $(r 2)$ : this species shows exceptional growth on termite mounds only. Ficus exasperata: 1.5 years ( $(\mathrm{s} 1)$.

Photos D. Louppe. 


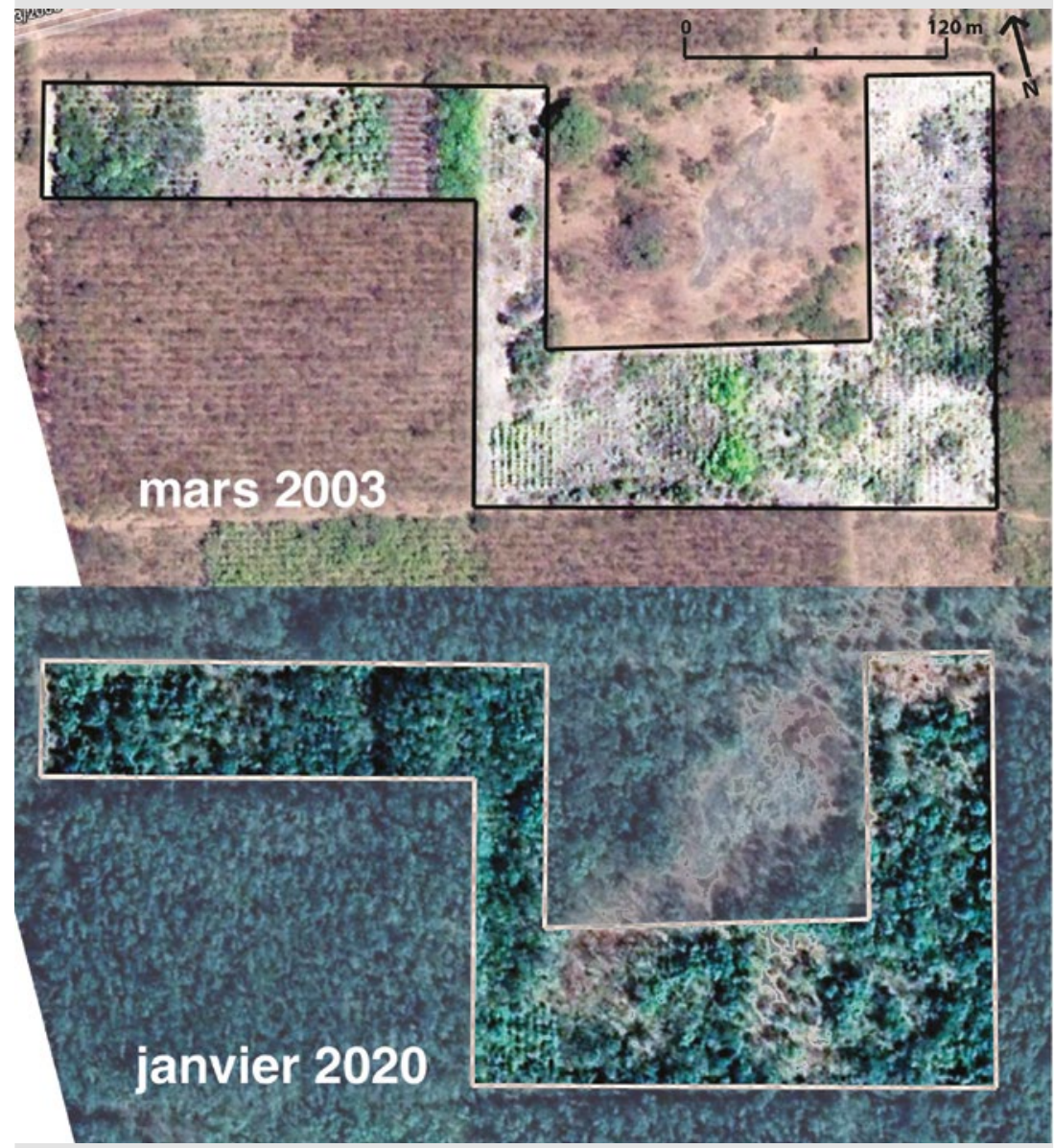

Photo 4.

Vues aériennes de l'arboretum en mars 2003 et en janvier 2020 (source : Google Earth). En 2003, les plantations sont encore jeunes et les espèces autochtones n'ont pas encore envahi les parcelles. Les espèces caducifoliées sont peu visibles sur cette photo prise en fin de saison sèche, d'autant que la sécheresse a été forte en 2002 car le lac de barrage est pratiquement vide. On peut observer des emplacements où le feuillage est plus dense car la fertilité y est meilleure à cause de la présence de termitières. Ceci est très nettement visible sur les deux taches vert clair de la parcelle de Blighia sapida. En 2020, le couvert est fermé même dans les parcelles où tous les arbres plantés ont disparu, comme les acacias, ou ont connu une forte mortalité, comme le fromager. C'est le résultat d'une forte colonisation du terrain par des espèces autochtones zoochores mais aussi par des Gmelina arborea, une espèce exotique qui, par sa croissance rapide, concurrence localement très fortement les arbres plantés. Cette espèce exotique aurait dû être éliminée dès son apparition mais cela n'a pas été le cas. Aerial views of the arboretum in March 2003 and January 2020. (Source: Google Earth). In 2003, the plantations are still young and the indigenous species have not yet invaded the plots. The deciduous species are not very visible on this photo taken at the end of the dry season, especially as the drought was severe in 2002 because the dam lake is practically empty. We can see places where the foliage is denser because the fertility is better due to the presence of termite mounds. This is clearly visible in the two light green patches in the Blighia sapida plot. In 2020, the canopy is closed even in plots where all the planted trees have disappeared, such as the acacia, or have experienced high mortality, such as the cheese tree. This is the result of a strong colonisation of the land by indigenous zoochorous species but also by Gmelina arborea, an exotic species which, by its rapid growth, competes locally very strongly with the planted trees. This exotic species should have been eliminated as soon as it appeared, but this was not the case. Photo D. Louppe.
Les différences de croissance hors et sur termitière sont considérables, montrant que Faidherbia albida a besoin d'un sol déjà fertile pour s'installer rapidement. Ceci confirme les premières constations de Geiger et al. (1992) et de Brouwer et al. (1992). Faidherbia albida ne semble donc pas pouvoir être utilisée directement pour restaurer la fertilité de sols dégradés ou trop fortement appauvris ainsi qu'on le préconise. Il convient donc, sur ces sols appauvris ou dégradés, de planter Faidherbia sur les vieilles termitières afin de profiter de leur fertilité pour un bon démarrage des plants. Si une dizaine d'arbres sont plantés par termitière, un parc arboré ne sera pas constitué d'arbres répartis de façon régulière dans l'espace mais de petits bosquets. En grandissant, les arbres vont améliorer la fertilité du sol dans leur environnement et permettre ainsi l'installation de nouveaux arbres pour former par la suite un parc assez dense. Sur les sols agricoles de bonne fertilité, ce problème ne se pose pas, donc le parc arboré peut être installé directement avec des écartements de $10 \times 10 \mathrm{~m}$.

Quatre espèces se sont montrées particulièrement performantes à 8,5 ans avec des surfaces terrières dépassant $9 \mathrm{~m}^{2} / \mathrm{ha}$ :

- Anogeissus leiocarpa avec une hauteur moyenne de près de $11 \mathrm{~m}$ et une surface terrière de 10,8 $\mathrm{m}^{2}$ / ha pour une densité de 1250 arbres/ ha ; cette espèce, pionnière et grégaire, est largement monodominante (planche photos 1) ;

- Pterocarpus erinaceus, malgré une croissance décourageante pendant les premières années (17 cm à 1,5 ans, $49 \mathrm{~cm}$ à 2,5 ans), a montré ensuite une croissance rapide, $158 \mathrm{~cm}$ à 3,5 ans et $8,8 \mathrm{~m}$ à 8,5 ans, avec une surface terrière de $10,0 \mathrm{~m}^{2} / \mathrm{ha}$ pour 816 arbres/ha (planche photos 1 );

- Terminalia schimperiana, malgré des problèmes de germination en pépinière, a montré une très bonne reprise en plantation puisqu'à 8,5 ans aucune mortalité n'était constatée ; la surface terrière est de $9,1 \mathrm{~m}^{2} /$ ha pour une hauteur moyenne de 6,3 m (photo 6) ;

- Ceiba pentandra semblait prometteuse avec une croissance initiale très rapide, soit près de $1 \mathrm{~m}$ en hauteur et $2 \mathrm{~cm}$ sur le diamètre par an, pour atteindre une surface terrière de $10,5 \mathrm{~m}^{2} /$ ha à 4,5 ans. Ensuite, la hauteur moyenne et la surface terrière stagnent. Des dessèchements de cimes et une mortalité (11\% par an) plus qu'inquiétants sont apparus la septième année et se sont poursuivis ensuite (planche photos 1). Un constat similaire avait été fait en Casamance (Vincenti, 1986 ; Louppe, 1992) et au Cameroun (Hautdidier et al, 2002), laissant penser que, en climat soudano-guinéen, cette espèce ne peut être plantée en peuplement qu'avec de très 


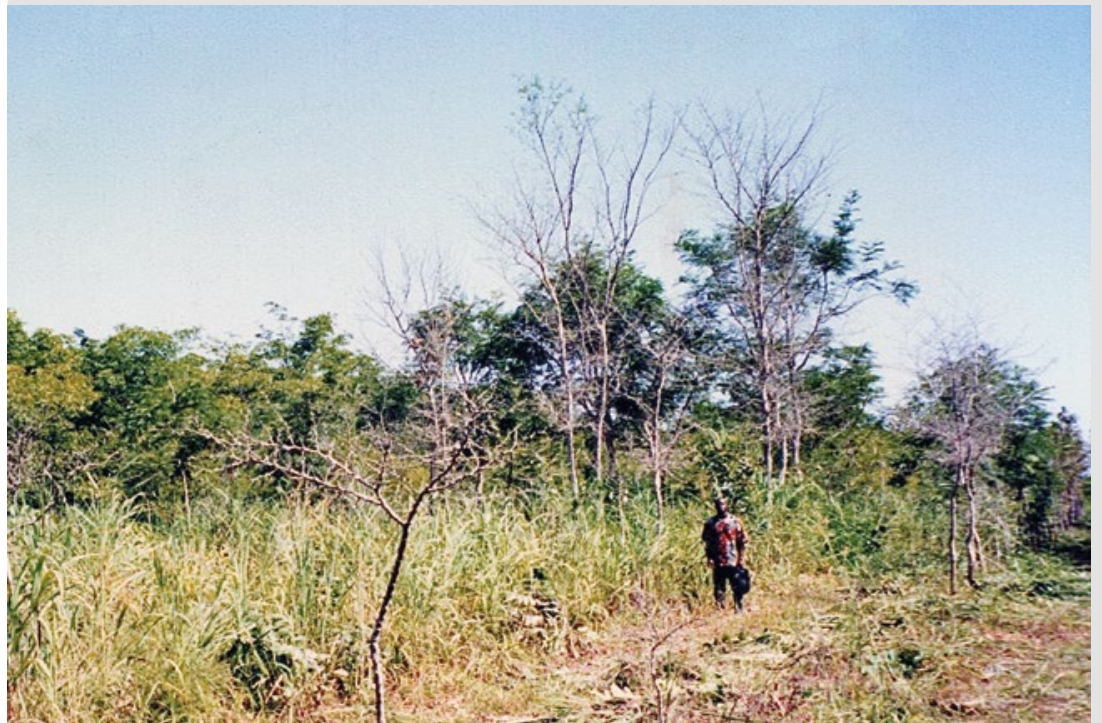

Photo 5.

Parcelle de Faidherbia albida âgée de 8,5 ans. La croissance très variable des arbres peut s'expliquer par la variabilité de la fertilité du sol. Le sol riche de la termitière, derrière l'homme dont la taille sert de référence, porte des arbres qui se sont développés incomparablement plus vite que ceux sur les sols environnants, montrant que Faidherbia est une espèce exigeante quant à la qualité des sols, au moins dans le jeune âge.

Plot of 8.5-year-old of Faidherbia albida. The highly variable growth of the trees can be explained by the variability of the soil fertility. The rich soil of the termite mound, behind the man whose height serves as a reference, bears trees that have grown incomparably faster than those on the surrounding soils, showing that Faidherbia is a demanding species in terms of soil quality, at least in its young age.

Photo D. Louppe.

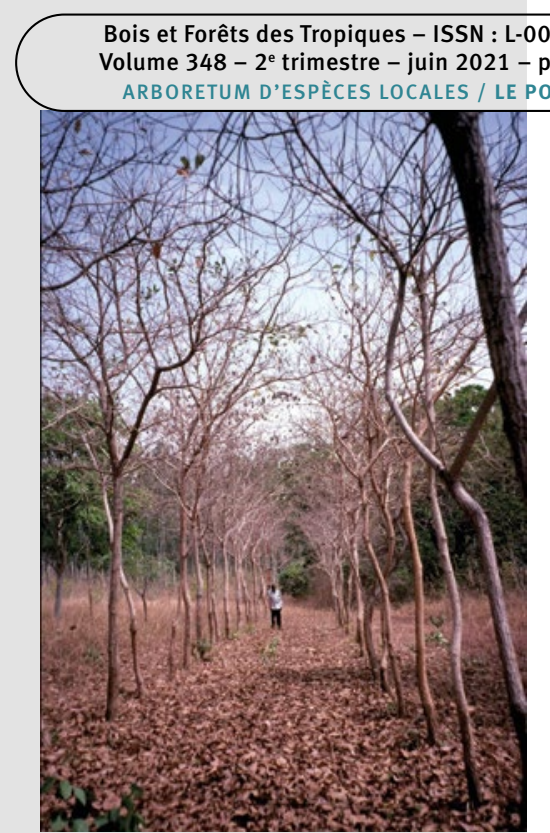

Photo 6.

Terminalia schimperiana âgé de 8,5 ans. L'importante litière qu'il produit couvre bien le sol et limite le développement des espèces adventices tant herbacées que ligneuses qui pourraient le concurrencer.

Terminalia schimperiana is 8.5 years old. The large amount of litter it produces provides good soil cover and limits the development of weeds and woody species that could compete with it.

Photo D. Louppe. grands écartements en raison de son comportement peu grégaire sous ce climat.

Les trois premières espèces présentent l'avantage de former un couvert dense qui élimine assez bien la strate herbacée et la concurrence des autres ligneux parce qu'ils se régénèrent très mal sous ce couvert.

\section{Résultats à 29 ans}

À partir de 2002, le suivi de ces plantations a été abandonné en raison de la période d'insécurité qu'a connue la Côte d'Ivoire. II n'y a plus eu de mesures entre 1999 et novembre 2019. Aucune sylviculture n'a été mise en œuvre comme cela était prévu : pas d'éclaircie, pas d'élimination des régénérations naturelles d'espèces locales ou exotiques, notamment de Gmelina arborea largement disséminée par les oiseaux. Ces espèces « indésirées » ont concurrencé ou dominé les arbres plantés dans cet arboretum, faussant certainement les résultats en les minimisant. L'impact de cette concurrence non souhaitée n'a pas été étudiée à ce jour mais mériterait de l'être.

Par exemple, Faidherbia albida a fini par disparaître car cette espèce ne supporte pas la concurrence d'autres espèces. C'est une espèce rudérale pionnière disséminée par le bétail dans les terres de culture où elle peut constituer des parcs arborés (Seignobos, 1996). Les paysans Sénoufo savent bien que le Faidherbia disparaît lorsque les terres sont mises en jachère longue.

Un autre facteur a été décisif pour la survie ou la mortalité des arbres : la très forte sécheresse de 2005-2006 (Boko-Koiadia et al., 2016). Faute d'observations faites dans les années qui ont suivi, il est impossible de savoir si elle a été ou non la cause majeure de la disparition totale ou partielle de certaines espèces.

Concurrence et sécheresse ont probablement été des facteurs cumulatifs. L'une sans l'autre n'aurait peut-être pas conduit aux effets observés en 2019.

Un troisième effet sur les résultats obtenus, également non étudié, est l'effet termitières. En effet, de nombreuses termitières cathédrales, dépassant deux mètres de haut, sont apparues, incluant souvent des arbres qui ne semblent pas souffrir de cette situation (photo 7). Le développement des termitières pendant la période d'abandon de l'arboretum 


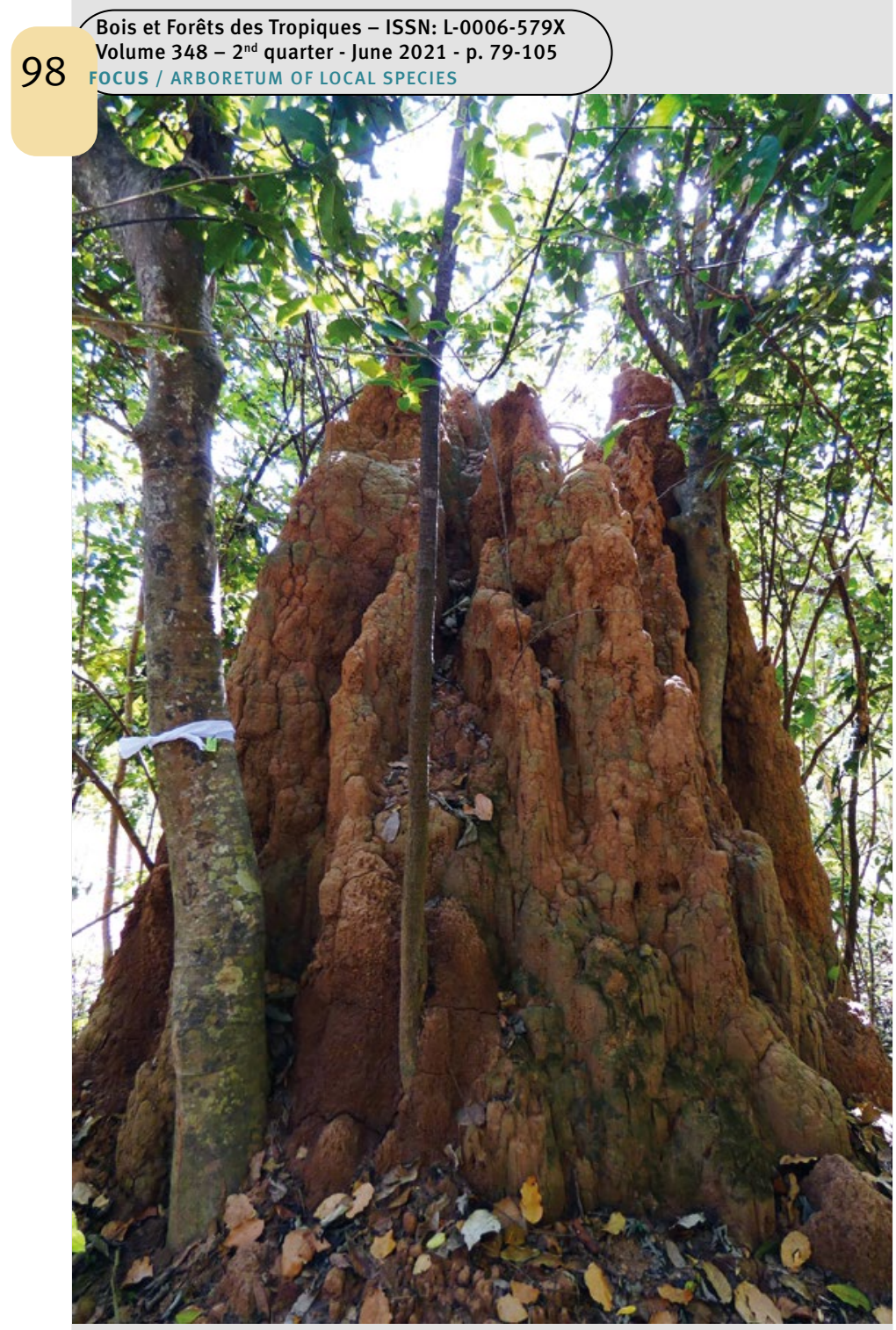

Photo 7.

Beaucoup de termitières cathédrales se sont développées dans les plantations au cours des dix dernières années. Elles étaient beaucoup moins nombreuses et surtout beaucoup moins développées en 2013. L'activité croissante des termites est probablement due à l'enrichissement du milieu par la matière organique de la litière. Dans l'ensemble, aucune des espèces plantées ne semble avoir eu de mortalité liée à la présence des termites.

Many cathedral termite mounds have developed in the plantations over the last ten years. They were much less numerous and especially much less developed in 2013. The increase in termite activity is probably due to the enrichment of the environment with organic matter from the litter. On the contrary, overall, none of the planted species seems to have had termite-related mortality. Photo D. Louppe.

pourrait être lié à l'augmentation de la matière organique disponible au sol résultant des retombées de litières et de bois mort. Une matière organique abondante permet d'alimenter un plus grand nombre de termites, donc des colonies, d'où l'augmentation de la taille des nids. La croissance des arbres à proximité de ces termitières est meilleure, ainsi que nous l'avons déjà noté plus haut. La dispersion des termitières entraîne une hétérogénéité de milieu qui se traduit par une hétérogénéité de la taille

des arbres d'une même espèce masquant les différences statistiques probables des traitements appliqués.

Le tableau VIII présente les résultats des mesures de novembre 2019.

Pour quatre espèces, nous disposons de tarifs de cubage élaborés chacun à partir du cubage intégral de 80 individus abattus en forêt de Badénou à environ $80 \mathrm{~km}$ de distance (Louppe et al., 1994 a, b, c, d) :

- Afzelia africana: VT =0,1271-0,5633 $\times \mathrm{C}+1,0608 \times \mathrm{C}^{2}$

- Anogeissus leiocarpa : VT $=-0,0826+0,8633 \times \mathrm{C}^{2}$

- Pterocarpus erinaceus :

$\mathrm{VT}=-0,0635-0,3949 \times \mathrm{C}+0,9617 \times \mathrm{C}^{2}$

- Parkia biglobosa : V =0,0935+0,1392 × $\mathrm{C}^{3}$

Avec VT = volume total (en $\left.\mathrm{m}^{3}\right)$ jusqu'à une découpe fin bout de $4 \mathrm{~cm}$ de diamètre, $C=$ circonférence du fût (en m) à 1,30 m de haut.

Ces tarifs sont valides entre 30 et plus de $250 \mathrm{~cm}$ de circonférence.

\section{Analyse des résultats à 29 ans}

Toutes les espèces, excepté Balanites aegyptiaca, étaient encore bien présentes à 8,5 ans avec au moins 430 arbres/ha, ce qui laissait présager des peuplements denses dans un avenir plus ou moins proche.

Cependant, à 29 ans, Acacia polyacantha, Faidherbia albida et Ficus exasperata avaient également disparu. Trois espèces n'étaient plus représentées que par quelques individus :

- Acacia sieberiana (survie : 2,2 \%), espèce préférant les sols argileux de bas-fonds temporairement inondés et peu adaptée aux sols de plateau (Arbonnier, 2019) ;

- Albizia zygia (2,7\%) ;

- Spondias mombin (2,8\%).

Ces sept espèces ne sont donc pas à conseiller pour des reboisements en plein sur des terres de plateau dans la région de Korhogo. Certaines peuvent néanmoins servir pour des reboisements en zone plus humide de basfond ou dans des systèmes agroforestiers.

Parmi les 15 espèces restantes, Ceiba pentandra (fromager) est la seule présentant un faible taux de survie $(6,3 \%)$ mais qui correspond néanmoins à 89 arbres/ ha, nombre suffisant pour constituer une futaie à l'avenir. Sa croissance est très lente avec seulement trois individus dont la hauteur est supérieure à $10 \mathrm{~m}$. Cette espèce, qui a montré des dessèchements de cimes dès sept ans, ne semble donc pas adaptée à la constitution de peuplements denses monospécifiques dans les conditions de l'expérimentation (planche photos 1). Pourtant le fromager est un arbre que l'on trouve régulièrement disséminé dans la région. Peut-être est-il très exigeant vis-à-vis de la fertilité du sol ? En effet un proverbe sénoufo dit "heureux celui qui a un fromager dans son champ ", sous-entendu " car celui-ci est fertile et les récoltes seront bonnes ". 
Sterculia setigera, bien qu'ayant eu un très bon démarrage (planche photos 3), se distingue par des dessèchements de cimes qui touchent presque la totalité des arbres. Pourtant c'est une espèce réputée pour croître sur des sols gravillonnaires et peu profonds mais qui ne forme jamais de bosquet. Il s'agit d'une espèce non grégaire à utiliser prudemment comme arbre isolé dans des terres de culture afin de produire une gomme alimentaire.

Ces deux espèces également ne sont pas recommandées pour des plantations, tout au moins dans les conditions de l'arboretum. Elles ont peut-être eu à souffrir plus que les autres de la concurrence des espèces qui se sont naturellement installées et développées au cours des vingt dernières années, d'autant plus qu'il n'y a eu ni entretien ni sylviculture. L'année de forte sécheresse a également pu jouer un rôle, notamment pour le fromager.

En l'absence de sylviculture, un critère qui nous paraît intéressant est le quotient ( $Q$ ) que nous définissons comme étant le rapport de la surface terrière des dominants (G Dom) à la surface terrière totale (G Tot) divisé par 100 (nombre d'arbres dominants par hectare) sur le nombre total d'arbres à l'hectare (N Tot) :

$$
Q=\frac{G \text { Dom } / G \text { Tot }}{100 / N \text { Tot }}
$$

Ce coefficient $Q$ a été construit pour caractériser l'homogénéité du peuplement et la part qu'ont les arbres d'avenir, les arbres dominants, dans la constitution de la futaie future. Ainsi, Q caractérise l'importance de la surface terrière des dominants par rapport à leur part, en nombre, dans la population. En effet, en n'utilisant que $G$ Dom/G Tot, on aurait naturellement une valeur élevée pour les parcelles avec un faible nombre d'individus et plus faible pour les peuplements denses. Le coefficient $Q$ veut éliminer ce biais et donner une réelle image du poids des dominants dans le peuplement. Plus $Q$ est élevé, plus les arbres dominants ont un poids important dans la population globale; plus il se rapproche de 1, plus les différences de taille entre les arbres dominants et le reste de la population sont faibles, donc plus le peuplement est homogène. Ce coefficient n'a d'intérêt que si l'on ne peut pas estimer les volumes individuels sur pied, quand il n'existe pas de tarif de cubage individuel fiable.

Pour les plantations étudiées ici, on a :

- $\mathrm{Q}>3$ pour Anogeissus leïocarpa, Sterculia setigera et Vitex doniana ;

- $3>$ Q > 2,5 pour Pterocarpus erinaceus, Afzelia africana, Cola cordifolia et Blighia sapida (qui est juste limite : 2,49 ); - 2,5>Q > 2 pour Parkia biglobosa et Pericopsis laxiflora.

Pour ces neuf espèces, les arbres dominants ont un rôle majeur dans la production, ce qui laisse supposer qu'une grande part des autres arbres sont de petite taille et auraient dû être éliminés lors des éclaircies s'il y en avait eu.

Les individus des autres espèces ont une croissance plus homogène.

$\mathrm{Si}$, au lieu des surfaces terrières, on compare le volume des 100 dominants à l'hectare au volume total de la parcelle, ces différences sont encore plus marquées, le volume des dominants rapporté au volume total (cubés à partir de $10 \mathrm{~cm}$ de diamètre) représente :

- 36,7 \% pour Anogeissus leiocarpa, avec une densité de 1084 arbres/ha ;

- $44,4 \%$ pour Pterocarpus erinaceus avec 753 arbres/ha ;

- 47,9\% pour Afzelia africana avec 759 arbres/ha ;

- 68,4 \% pour Parkia biglobosa avec 389 arbres/ha.

Ces données laissent penser qu'une sylviculture adaptée (éclaircies en temps utile) aurait permis de concentrer une partie supplémentaire de la production sur les arbres dominants pour obtenir des arbres de plus gros diamètre.

Les trois décennies (29 années) de suivi de cet arboretum montrent que, en dehors des problèmes que l'on peut rencontrer en pépinière, planter des espèces autochtones adaptées aux conditions climatiques locales nécessite d'en connaître l'écologie et notamment les exigences édaphiques. En choisissant mieux le site de plantation, par exemple en plantant Acacia sieberiana, Acacia polyacantha et Albizzia zygia non en haut de Caténa mais à proximité du fond de la vallée, on aurait amélioré leur survie et leur croissance. Si des espèces non grégaires comme Spondias mombin, Faidherbia albida, Ceiba pentandra et Sterculia setigera avaient été plantées à de très grands écartements dans des terres cultivées, elles auraient probablement pu se développer de manière satisfaisante et, de plus, n'auraient pas eu à souffrir de la concurrence des espèces qui se sont installées naturellement.

Il est remarquable d'observer que cet arboretum a été envahi par de nombreuses espèces qui se sont régénérées naturellement et ont ainsi recréé une jeune forêt dense sèche même dans les parcelles où les espèces plantées ont disparu (photo 4). Si l'on exclut les régénérations de Daniellia oliveri et d'Isoberlinia doka, issues de drageons ou du bouturage naturel des racines des arbres abattus lors de la préparation du terrain, la majorité des espèces proviennent de graines apportées par les oiseaux ou par des petits mammifères. Gmelina arborea est une espèce exotique qui fructifie abondamment. Elle s'est ainsi répandue dans toute la station. Cette espèce est invasive, vu sa rapidité de croissance, et domine le peuplement d'espèces autochtones qu'elle concurrence. Une autre espèce, très invasive aussi, est locale : il s'agit de Zanthoxylum zanthoxyloides (Lam.) Zepern. \& Timler qui forme un sous-bois parfois dense et gênant car cette espèce est épineuse jusque sur les feuilles. Un travail de recherche, très utile, serait à mener pour identifier toutes les espèces qui se réinstallent en sous-bois et évaluer leur importance dans la reconstitution de la biodiversité locale, ainsi que leur position par rapport aux termitières.

Parmi les espèces plantées, certaines sont fortement grégaires et forment des peuplements purs et denses qui éliminent ou limitent la végétation adventice : Anogeissus leiocarpus, Pterocarpus erinaceus, Blighia sapida et Cola cordifolia. Les deux premières, productrices d'un bois d'œuvre de qualité, s'avèrent être les plus intéressantes avec une croissance annuelle de 6,4 et $5,0 \mathrm{~m}^{3} / \mathrm{ha}$, productivité qui n'est pas du tout négligeable et est comparable à la croissance des espèces de bois d'œuvre de régions tem- 


\section{Tableau VIII.}

Observations faites à 29 ans sur 15 espèces autochtones de l'arboretum de Lataha.

Les espèces colorées en jaune représentent les espèces les plus productives.

\begin{tabular}{|c|c|c|c|c|c|c|c|}
\hline Espèces & $\begin{array}{c}\text { Anogeissus } \\
\text { leiocarpa }\end{array}$ & $\begin{array}{c}\text { Afzelia } \\
\text { africana }\end{array}$ & $\begin{array}{l}\text { Blighia } \\
\text { sapida }\end{array}$ & $\begin{array}{c}\text { Ceiba } \\
\text { pentandra }\end{array}$ & $\begin{array}{c}\text { Cola } \\
\text { cordifolia }\end{array}$ & $\begin{array}{c}\text { Daniellia } \\
\text { oliveri }\end{array}$ & $\begin{array}{c}\text { Detarium } \\
\text { microcarpum }\end{array}$ \\
\hline S parcelle $\left(m^{2}\right)$ & 784 & 1568 & 1568 & 1568 & 784 & 1568 & 1568 \\
\hline $\mathrm{N}$ vivants & 85 & 119 & 78 & 14 & 105 & 48 & 112 \\
\hline N plantés & 112 & 224 & 224 & 224 & 112 & 224 & 224 \\
\hline Taux de survie (\%) & 75,9 & 53,1 & 34,8 & 6,3 & 93,8 & 21,4 & 50,0 \\
\hline Densité/ha & 1084 & 759 & 497 & 89 & 1339 & 306 & 714 \\
\hline G parcelle $\left(\mathrm{cm}^{2}\right)$ & 19363 & 16601 & 8924 & 5421 & 8458 & 1816 & 6296 \\
\hline $\mathrm{G} / \mathrm{ha}\left(\mathrm{m}^{2}\right)$ & 24,70 & 10,6 & 5,69 & 3,46 & 10,79 & 1,16 & 4,02 \\
\hline VT parcelle > D = $10\left(\mathrm{~m}^{3}\right)$ & 14,629 & 9,11 & - & - & - & - & - \\
\hline $\mathrm{V} / \mathrm{ha}\left(\mathrm{m}^{3}\right)$ & 186,594 & 58,119 & - & - & - & - & - \\
\hline AAM/ha (m³/ha/an) & 6,434 & 2,0 & - & - & - & - & - \\
\hline $\mathrm{N}$ dominants/parcelle & 8 & 16 & 16 & 14 & 8 & 16 & 16 \\
\hline $\mathrm{H}(\mathrm{m})$ échantillon & 19,0 & 13,5 & 9,0 & 10,0 & 6,5 & 9,0 & 7,0 \\
\hline D moyen $(\mathrm{cm})$ & 15,6 & 12,8 & 11,1 & 21,3 & 9,5 & 6,4 & 7,6 \\
\hline Dg dominants $(\mathrm{cm})$ & 29,7 & 22,2 & 19,1 & 22,2 & 17,3 & 9,5 & 11,6 \\
\hline G Dom/parcelle $\left(\mathrm{cm}^{2}\right)$ & 5559 & 6217 & 4563 & & 1872 & 1136 & 1689 \\
\hline G Dom/ha $\left(m^{2}\right)$ & 7,09 & 3,97 & 2,91 & & 2,39 & 0,72 & 1,08 \\
\hline V Dom/parcelle $\left(\mathrm{m}^{3}\right)$ & 5,370 & 4,369 & - & - & - & - & - \\
\hline Vmoy Domin $\left(m^{3}\right)$ & 0,671 & 0,273 & - & - & - & - & - \\
\hline Vdom/ha $\left(m^{3} / h a\right)$ & 68,491 & 27,862 & - & - & - & - & - \\
\hline AAM/ha Dom (m³/ha/an) & 2,362 & 0,961 & - & - & - & - & - \\
\hline N Dom/N Tot (\%) & 9,4 & 13,4 & 20,5 & 100,0 & 7,6 & 33,3 & 14,3 \\
\hline G Dom/ G Tot (\%) & 28,7 & 37,5 & 51,1 & 0,0 & 22,1 & 62,6 & 26,8 \\
\hline V Dom/V Tot (\%) & 36,7 & 47,9 & - & - & - & - & - \\
\hline
\end{tabular}

$\mathrm{S}$ : surface ; N : nombre ; $\mathrm{G}$ : surface terrière ; VT : volume total ; AAM : accroissement annuel moyen : $\mathrm{H}$ : ordre de grandeur de la hauteur ; $\mathrm{D}$ : diamètre moyen ; Dg : diamètre quadratique moyen ;

$\mathrm{G}$ Dom et $\mathrm{V}$ Dom : surface terrière et volume des 100 plus gros arbres à l'hectare ;

AAM Dom : accroissement annuel moyen des 100 plus gros arbres à l'hectare ;

$\mathrm{N}$ Tot, $\mathrm{G}$ Tot et $\mathrm{V}$ Tot : nombre d'arbres total, surface terrière et volume total de la parcelle.

pérées. En France, la productivité moyenne des forêts entre 2005 et 2012, tous lieux et toutes espèces confondus, est de $5,8 \pm 0,1 \mathrm{~m}^{3} /$ ha par an ${ }^{4}$.

À Lataha, on est encore loin de pouvoir récolter du bois sciable mais la foresterie est une culture de long terme, surtout si l'on veut réinstaller des espèces locales devenues rares en raison de la disparition des massifs forestiers et de la surexploitation. Deux autres espèces semblent pouvoir être cultivées en peuplement monospécifique avec une croissance satisfaisante, à savoir Afzelia africana et Terminalia schimperiana, qui ont une surface terrière supérieure à $10 \mathrm{~m}^{2} / \mathrm{h}$ à 29 ans. La faible productivité du lingué (Afzelia), $2 \mathrm{~m}^{3} / \mathrm{ha} / \mathrm{an}$, doit être relativisée car la parcelle a été envahie par d'autres espèces d'arbres, ce qui n'est pas le cas des parcelles d'Anogeissus et de Pterocarpus dont le couvert très dense a empêché la prolifération des espèces adventices.

${ }^{4}$ https://inventaire-forestier.ign.fr/IMG/pdf/IGD 2015 CRITERE-3.pdf
Cet arboretum montre aussi que les résultats obtenus au cours des premières années ne préjugent en rien de l'avenir des plantations. Par exemple Acacia polyacantha, Acacia sieberiana et Albizia zygia qui ont montré une très bonne croissance pendant les premières années, surtout sur termitière, voient leur population dépérir rapidement après six années.

Il est dommage que l'absence de suivi pendant près de deux décennies n'ait pas permis de déterminer les causes de la disparition de ces espèces pourtant bien adaptées au climat, ainsi que celle de Faidherbia albida, Ficus exasperata et Spondias mombin. On peut supposer que les Acacia et Albizia ont périclité car ils n'ont pas été installés dans des zones humides de bas-fond qui leur conviennent mieux, que Faidherbia et Spondias, espèces agroforestières, n'ont pas supporté la concurrence d'autres arbres, et que le Ficus est une espèce pionnière à durée de vie limitée. Cependant, ces explications ne sont certainement pas complètes. Déterminer les causes exactes de leur disparition aurait permis de 
Observations made at 29 years on 15 indigenous species of the Lataha arboretum.

The species coloured in yellow represent the most productive species.

\begin{tabular}{|c|c|c|c|c|c|c|c|}
\hline $\begin{array}{l}\text { Parkia } \\
\text { biglobosa }\end{array}$ & $\begin{array}{c}\text { Pericopsis } \\
\text { laxiflora }\end{array}$ & $\begin{array}{c}\text { Pterocarpus } \\
\text { erinaceus }\end{array}$ & $\begin{array}{l}\text { Sterculia } \\
\text { setigera }\end{array}$ & $\begin{array}{c}\text { Tamarindus } \\
\text { indica }\end{array}$ & $\begin{array}{c}\text { Terminalia } \\
\text { macroptera }\end{array}$ & $\begin{array}{c}\text { Terminalia } \\
\text { schimperiana }\end{array}$ & $\begin{array}{c}\text { Vitex } \\
\text { doniana }\end{array}$ \\
\hline 1568 & 896 & 784 & 1568 & 1568 & 784 & 392 & 448 \\
\hline 61 & 66 & 59 & 119 & 33 & 42 & 29 & 28 \\
\hline 224 & 128 & 112 & 224 & 224 & 112 & 56 & 64 \\
\hline 27,2 & 51,6 & 52,7 & 53,1 & 14,7 & 37,5 & 51,8 & 43,8 \\
\hline 389 & 737 & 753 & 759 & 210 & 536 & 740 & 625 \\
\hline 6211 & 4711 & 17034 & 10022 & 2683 & 4447 & 4546 & 1780 \\
\hline 3,96 & 5,26 & 21,73 & 6,39 & 1,71 & 5,67 & 11,60 & 3,97 \\
\hline 3,864 & - & 11,375 & - & - & - & - & - \\
\hline 24,641 & - & 145,095 & - & - & - & - & - \\
\hline 0,850 & - & 5,003 & - & - & - & - & - \\
\hline 16 & 9 & 8 & 16 & 16 & 8 & 4 & 5 \\
\hline 11,0 & 7,5 & 18,0 & 8,5 & 9,0 & 10,5 & 13,0 & 10,0 \\
\hline 10,3 & 9,2 & 17,4 & 9,3 & 9,4 & 11,0 & 13,7 & 7,8 \\
\hline 17,2 & 13,7 & 31,6 & 13,7 & 12,7 & 11,9 & 19,0 & 16,0 \\
\hline 3696 & 1320 & 6281 & 4227 & 2040 & 893 & 1129 & 1007 \\
\hline 2,36 & 1,47 & 8,01 & 2,70 & 1,30 & 1,14 & 2,88 & 2,25 \\
\hline 2,643 & - & 5,054 & - & - & - & - & - \\
\hline 0,165 & - & 0,632 & - & - & - & - & - \\
\hline 16,859 & - & 64,471 & - & - & - & - & - \\
\hline 0,581 & - & 2,223 & - & - & - & - & - \\
\hline 26,2 & 13,6 & 13,6 & 13,4 & 48,5 & 19,0 & 13,8 & 17,9 \\
\hline 59,5 & 28,0 & 36,9 & 42,2 & 76,0 & 20,1 & 24,8 & 56,6 \\
\hline 68,4 & - & 44,4 & - & - & - & - & - \\
\hline
\end{tabular}

mieux préciser les conditions nécessaires à leur plantation. Il en va de même pour Sterculia setigera, une espèce rustique qui pourtant présente des dessèchements de cimes quasi généralisés.

Enfin, pour l'établissement des plantations, il faudrait prendre en compte les micro-variations des qualités de sols, souvent liées à la présence de termitières actives ou mortes. Les espèces les plus exigeantes en matière de fertilité devraient être plantées sur ces termitières avec des espèces moins exigeantes en plantations intercalaires. Ceci plaide pour l'installation de plantations en mélange et non de plantations monospécifiques, par exemple des plantations de Afzelia sur les termitières avec Anogeissus, Pterocarpus et d'autres espèces dans les intervalles. On reconstituerait ainsi assez rapidement un boisement diversifié proche des formations naturelles climaciques, favorable à la biodiversité tant végétale qu'animale et producteur de services écosystémiques bénéfiques.

\section{Conclusion}

L'initiative pour la restauration des paysages forestiers africains (AFR100) a pour objectif de restaurer 100 millions d'hectares de forêts disparues ou dégradés d'ici 2030 sur les 700 millions d'hectares de terres dégradées que compte le continent ${ }^{5}$, engagement pris à l'occasion du Bonn Challenge et de la Déclaration de New York sur les forêts. Le reboisement par la création de puits de carbone est une manière aussi de lutter contre le changement climatique et la dégradation des conditions favorables à l'agriculture, aux animaux et aux humains. La Côte d'Ivoire espère reconstituer le couvert forestier sur $20 \%$ de son territoire d'ici 2030 , soit 6,45 millions d'hectares, alors que le couvert actuel s'élève à environ 2 millions d'hectares. Les résultats présentés ci-dessus doivent contribuer à la réalisation de cet objectif dans les zones de savanes du Nord ivoirien en conseillant

${ }^{5}$ https://afr100.org/sites/default/files/AFR100\%200verview FR.pdf 
des espèces locales et les techniques pour conserver, voire restaurer la diversité végétale et améliorer les services écosystémiques. Cela ne concerne pas seulement les grandes plantations étatiques ou privées mais aussi les petits boisements ruraux et l'intégration des arbres, sous diverses formes, dans les systèmes agroforestiers.

Ces résultats fiables n'ont pu être obtenus que grâce au suivi à long terme des plantations expérimentales. La station de Lataha est la seule station ancienne de la zone soudano-guinéenne qui, semble-t-il, soit encore préservée en Afrique de l'Ouest francophone. L'arboretum qui a été présenté ici ne représente qu'une faible partie (environ $3 \%$ ) des expérimentations qui y ont été installées avant 1999. En 2019, nous avons mesuré dans cette station 5817 arbres de 35 espèces locales différentes (Hérault et al., 2020), donc bien plus que les arbres présents dans l'arboretum et bien moins que tous les arbres des espèces locales (55 espèces testées entre 1988 et 1991) plantées dans la station. De nombreuses informations sont donc encore à récolter, même sans prendre en compte les espèces exotiques testées (40 espèces introduites entre 1988 et 1991) (Louppe et al., 1992). En 32 ans, la station est devenue une forêt dense d'une centaine d'hectares comme on ne peut plus en voir que dans les relictes forestières de taille très limitée que sont les bois sacrés. Cette station est unique et mérite que des chercheurs permanents y reviennent pour en retirer, tant qu'il en est encore temps, le maximum d'informations pour le développement des plantations forestières dans la zone soudano-guinéenne de la sous-région. Au moment de l'installation de tous ces dispositifs, nous étions trois chercheurs appuyés par des missions de spécialistes et par des étudiants réalisant leurs mémoires de fin d'études d'ingénieur forestier. Nous disposions de financements extérieurs
(Union européenne et Banque africaine de développement) pour le fonctionnement de la station. Un travail considérable a été abattu, mais insuffisamment diffusé et surtout inabouti. Aujourd'hui, valoriser les acquis, mesurer et analyser le matériel sur pied, mener de nouvelles études complémentaires permettrait de répondre aux nouveaux questionnements liés aux évolutions climatiques, à celles des populations et de leurs besoins, aux relations agriculture/ arbres/forêts.

L'état forestier actuel de la station permet d'envisager de nouveaux thèmes de recherche comme la recolonisation spontanée de l'espace par des espèces locales, l'impact des termites et de la faune du sol, l'importance des symbioses, l'équilibre entre espèces, la productivité de ces milieux maintenant fermés et leurs rôles écologiques. Il permettrait aussi d'étudier l'état des zones mises en défens depuis 32 ans, zones envahies par des lianes qui n'existaient pas auparavant, et bien d'autres sujets qu'il serait pertinent d'aborder pour le développement futur des forêts de zone de savane de la Côte d'Ivoire et des pays voisins.

Cet arboretum montre qu'une sylviculture d'espèces soudano-guinéennes est possible, même si la croissance d'espèces exotiques comme Eucalyptus camaldulensis est incomparablement plus rapide.

Toutefois, si l'on compare l'Anogeissus ou le Pterocarpus au teck (Tectona grandis L.f.), une espèce exotique qui produit un excellent bois mais qui est très exigeante quant à la fertilité des sols, les différences de productivité sont nettement moins perceptibles.

Il est souhaitable que deux sylvicultures coexistent : les plantations d'espèces exotiques à croissance rapide pour répondre rapidement aux besoins en bois des populations et des plantations d'espèces locales, en mélange

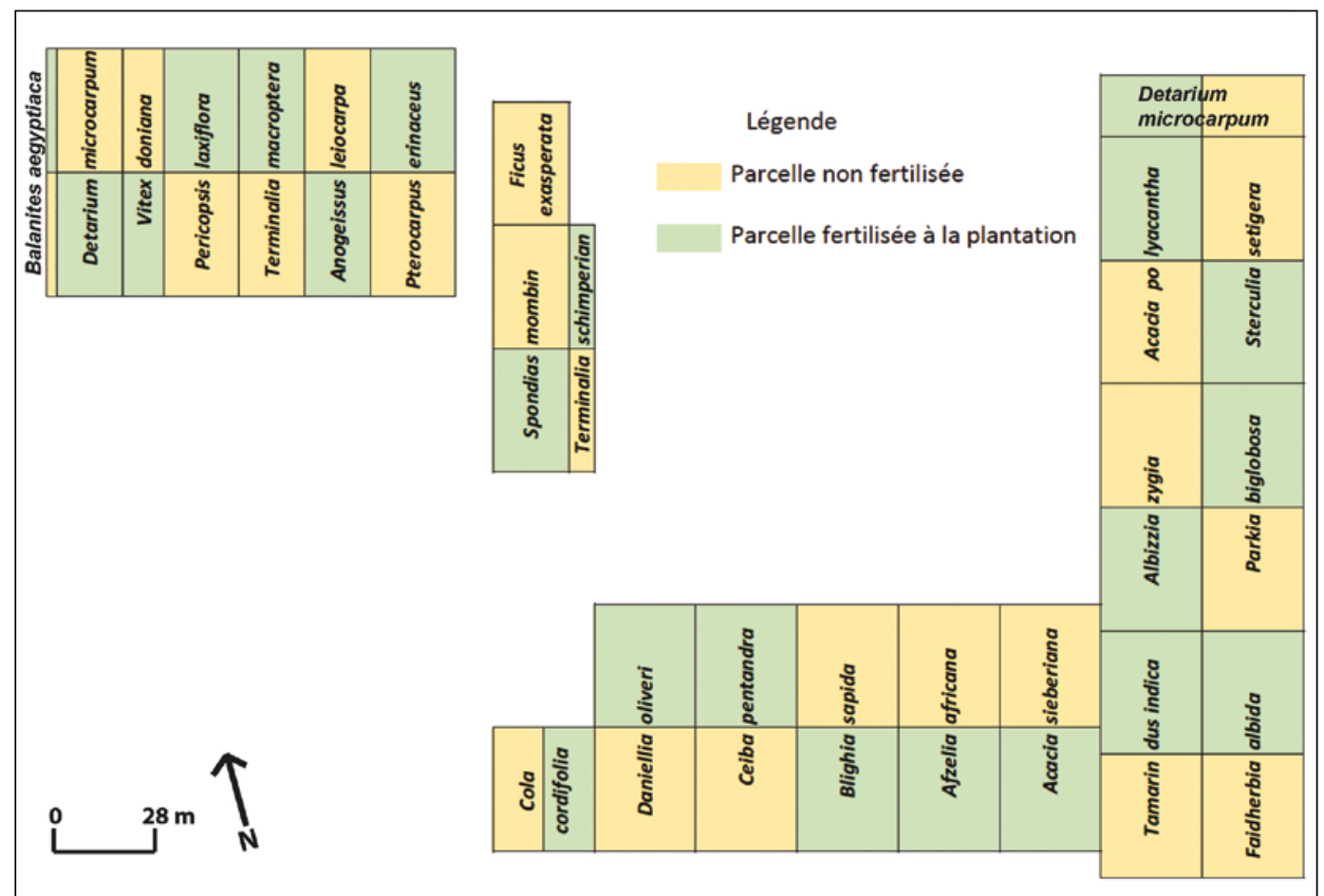

Figure 3.

Plan de l'arboretum 90-01 de Lataha. Les parcelles en vert sont celles qui ont reçu une fertilisation à la plantation ; celles en jaune n'ont pas été fertilisées.

Map of Lataha Arboretum 90-01. Plots in green are those that were fertilised at planting; those in yellow were not fertilised. par petits placeaux, pour reconstituer la diversité floristique locale et fournir une vaste gamme de produits ligneux et non ligneux très appréciés des populations mais devenus rares.

Le financement de beaucoup de projets de plantation s'arrête après trois ou quatre ans, le bailleur considérant que les arbres n'ont plus besoin d'être entretenus et peuvent se débrouiller seuls. Mais est-ce réellement le cas pour des plantations d'espèces soudano-guinéennes dont la phase d'installation, marquée par une croissance initiale lente, peut durer plusieurs années ? Cette phase de croissance aérienne lente correspond 
à l'installation du système racinaire, lequel doit explorer un important volume de sol pour permettre à l'arbre de s'alimenter en eau pendant la période de feuillaison qui démarre bien avant l'installation de la saison des pluies, dès que l'humidité atmosphérique commence à remonter.

La réussite des reboisements en zone soudano-guinéenne repose donc sur des financements de longue durée accompagnés du personnel qualifié indispensable pour assurer la gestion de ces nouvelles forêts.

La réussite des reboisements repose aussi sur une bonne connaissance des espèces à planter et cette connaissance dépend de la qualité des recherches effectuées. Ainsi, il est indispensable de reprendre au plus tôt, et avec des équipes suffisantes, les recherches dans la station de Lataha, près de Korhogo.

Enfin, il est indispensable que les projets acquièrent la confiance des populations locales, comme cela a été le cas ici, où une présence permanente du Centre national de recherche agricole (CNRA) et un simple contrat verbal passé en 1999 entre les chefs de village et un chercheur expatrié sur le départ ont suffi à assurer l'intégrité de cette station et des parcelles expérimentales pendant ces trois décennies et jusqu'à aujourd'hui.

\section{Remerciements}

Cette recherche de longue haleine n'aurait jamais pu se faire sans les populations des villages de Lataha et de Séridiakaha qui, en 1988 , ont cédé 100 ha de leurs terres poury installer une station de recherche forestière qu'ils ont contribué à protéger depuis sa création. Ces travaux n'auraient pu se faire sans la persévérance de la recherche forestière et agronomique ivoirienne, d'abord du Centre technique forestier tropical, puis de l'Institut des forêts et enfin du Centre national de recherche agricole (CNRA).

Entre 1988 et 1999, cette recherche a été financée par la Côte d'Ivoire avec l'appui de l'Union européenne, de la Banque africaine de développement et du Centre de coopération internationale en recherche agronomique pour le développement (Cirad) qui a mis à disposition un chercheur expatrié pendant 12 années. Depuis 1999, l'entretien de la station est assuré par le CNRA. La campagne de mesures de 2019 a été financée par le Fonds interprofessionnel pour la recherche et le conseil agricoles (FIRCA).

Que soient aussi remerciés tous les agents du CNRA qui ont travaillé sur cette station, dont certains depuis l'origine jusqu'à aujourd'hui. Ces plantations sont, en quelque sorte, leurs enfants et ils y sont fort attachés.

\section{Note liminaire}

Cet arboretum a seulement fait l'objet d'une courte communication au Congrès forestier mondial d'Antalya (Turquie) en 1997 (Louppe et Ouattara, 1997) et d'un article dans une revue scientifique en 2020 , lequel ne présentait que des résultats partiels de la campagne de mesures de novembre 2019 (Hérault et al., 2020). Toutes les informations et les données présentées dans le présent article sont extraites de rapports produits entre 1990 et 1997 par l'équipe pilotée par Dominique Louppe et N'Klo Ouattara, respectivement chef du programme de recherches forestières en zones de savanes de Côte d'Ivoire et chef de la station de Lataha. Les références à ces rapports, listés ci-dessous, n'ont pas été reprises dans le texte afin de ne pas le surcharger inutilement. À noter que les résultats des mesures de 1997 et 1999 sont originaux car jamais présentés jusqu'ici, même dans un rapport de littérature grise.

\section{Références}

Alexandre D. Y., 1977. Régénération naturelle d'un arbre caractéristique de la forêt équatoriale de Côte-d'Ivoire : Turraeanthus africana Pellegr. Ecologia Plantarum, 12 (3) : 241-262. https://core.ac.uk/download/pdf/39880712. pdf

Alexandre D. Y., 1993. Quelques observations sur la physiologie des semences et des plantules forestières de la zone du Nazinon. In : Somé L., De Kam M. (éds), Les problèmes de semences forestières, notamment en Afrique. Actes finaux du Symposium du Groupe de travail IUFRO P.2.04.00 "Problèmes des semences », Ouagadougou, Burkina Faso, 23-28 novembre 1992. Leiden, Pays-Bas, Backhuys, 203-209. ht.ps://horizon.documentation. ird.fr/exl-doc/pleins textes/pleins textes $6 / \mathrm{b}$ fdi 47 48/010010127.pdf

Arbonnier M., 2019. Arbres, arbustes et lianes d'Afrique de l'Ouest. $4^{\mathrm{e} e}$ édition. Versailles, France, Éditions Quæ, 776 p. https://www.quae.com/produit/1554/9782759225484/ arbres-arbustes-et-lianes-d-afrique-de-l-ouest

Aubréville A., 1950. Flore forestière soudano-guinéenne : A.O.F., Cameroun, A.E.F. Paris, France, Société d'éditions géographiques, maritimes et coloniales, $523 \mathrm{p}$.

Bellefontaine R., Meunier Q., Ichaou A., Morin A., Mapongmetsem P.-M., Belem B., et al., 2018. La régénération par graines et par multiplication végétative à faible coût (drageons et boutures de segments de racine). Montpellier, France, CIRAD, 463 p. https://agritrop.cirad.fr/587606/

Berhaut J., 1967. Flore du Sénégal. 2e édition. Dakar, Sénégal, Éditions Clairafrique, 486 p.

Billand A., Ousmane D. S., 1991. Amélioration des ligneux Soudano-Sahéliens. Activités 1990-1991, Stratégies et Perspectives. Nogent-sur-Marne, France, Cirad-CTFT, 205 p. https://agritrop.cirad.fr/305004/

Boko-Koiadia A. N., Guéladio C., Brama K., Dedy S., 2016. Variabilité climatique et changements dans l'environnement à Korhogo en Côte d'Ivoire : Mythes ou réalité ? European Scientific Journal, 12 (5) : 158-176. http:// dx.doi.org/10.19044/esj.2016.v12n5p158

Brouwer J., Geiger S. C., Vandenbeldt R. J., 1992. Variability in the growth of Faidherbia albida: a termite connection? In: Vandenbeldt R. J. (ed.). Faidherbia albida in the West African semi-arid tropics. Proceedings of a workshop, 22-26 April 1991, Niamey, Niger. Nairobi, Kenya, International Centre for Research in Agroforestry, 
131-135. http://oar.icrisat.org/991/1/RA 00220.pdf

Brunck F., Colonna J.-P., Dommergues Y., Ducousso M., Galiana A., Prin Y., et al., 1990. La maîtrise de l'inoculation des arbres avec leurs symbioses racinaires. Synthèse d'une sélection d'essais au champ en zone tropicale. Bois et Forêts des Tropiques, 223 : 24-42. https://agritrop. cirad.fr/418308/1/document 418308.pdf

CNSF (Centre de semences forestières), 2012. Catalogue des semences forestières 2012-2015. Ouagadougou, Burkina Faso, Ministère de l'Environnement et du Développement durable, 19 p. http://cnsf.bf/sites/default/ files/catalogue $\% 20 \% 20$ de $\% 20$ semences.pdf

Cuny P., Sanogo S., Sommer N., 1997. Arbres du domaine soudanien. Leurs usages et leur multiplication. Sikasso, Mali, Institut d'économie rurale et Intercoopération, 123 p. https://www.doc-developpement-durable.org/ file/Culture/Arbres-Bois-de-Rapport-Reforestation/livresguides/Arbres\%20du\%20domaine\%20soudanais-Livre. $\underline{\mathrm{pdf}}$

Fortuner R., Couturier G., 1983. Les nématodes parasites de plantes de la forêt de Taï (Côte d'Ivoire). Revue de Nématologie, 6 (1) : 3-10. https://horizon.documentation.ird.fr/exl-doc/pleins textes/pleins textes 5/pt5/ nemato/3223.pdf

Geerling C., 1982. Guide de terrain des ligneux sahéliens et soudano-guinéens. Wageningen, Pays-Bas, H. Veenman \& Zonen B. V., 340 p. https://edepot.wur. $\mathrm{nl} / 299935$

Geiger S. C., Vandenbeldt R. J., Manu A., 1992. Preexisting soil fertility and the variable growth of Faidherbia albida. In: Vandenbeldt R. J. (ed.). Faidherbia albida in the West African semi-arid tropics. Proceedings of a workshop, 22-26 April 1991, Niamey, Niger. Nairobi, Kenya, International Centre for Research in Agroforestry, 121-125. http://oar.icrisat.org/991/1/RA 00220.pdf

Germani G., Baujard P., Luc M., 1985. La lutte contre les nématodes dans le bassin arachidier sénégalais, Paris, France, Orstom, 17 p. https://horizon.documentation. ird.fr/exl-doc/pleins textes/pleins textes $5 / \mathrm{b}$ fdi 30 30/32223.pdf

Giffard P.-L., 1974. L’arbre dans le paysage sénégalais. Sylviculture en zone tropicale sèche. Dakar, Sénégal, Centre technique forestier tropical, 452 p. https://agritrop.cirad.fr/336905/

Harris I., Osborn T. J., Jones P., Lister D. H., 2020. Version 4 of the CRU TS monthly high-resolution gridded multivariate climate dataset. Nature, Scientific Data 7: 109. https://rdcu.be/b3nUI

Hautdidier B., Ntoukpa M., Njiti C., Tapsou Dawang M., 2002. Un bilan des essais forestiers et agroforestiers du Nord-Cameroun. Année 2001-2002. Cameroun, Irad-Prasac-Cirad, 112 p. https://agritrop.cirad.fr/551319/1/ document 551319.pdf

Hérault B., N'Guessan K. A., Ouattara N., Ahoba A., Bénédet F., Coulibaly B., et al., 2020. The long-term performance of 35 tree species of sudanian West Africa in pure and mixed plantings. Forest Ecology and Management, 468: 118171, 11 p. https://doi.org/10.1016/i. foreco.2020.118171

Louppe D., 1992. Productivité des formations forestières sous climat soudano-guinéen. Approche bibliographique. Côte d'Ivoire, Cirad-Forêt, 24 p. https://agritrop.cirad. fr/321932/1/ID321932.pdf

Louppe D., 1993. Espèces ligneuses soudaniennes et soudano-guinéennes testées en plantation. Document de travail. Analyse de la banque de données «Essais de sylviculture tropicale » du Cirad-Forêt. Montpellier, France, Cirad-Forêt, 41 p. https://agritrop.cirad.fr/597033/

Louppe D., Ouattara N., 1990. Rapport annuel 1989 de la station CTFT de Korhogo. Côte d'Ivoire, 24 p. https:// agritrop.cirad.fr/337173/1/document 337173.pdf

Louppe D., Ouattara N., 1990. Deux années de recherches à la station CTFT de Lataha. CTFT-Cirad, 47 p. https://agritrop.cirad.fr/337156/1/document 337156.pdf

Louppe D., Ouattara N., Koffi O., 1991. Projet de recherche agroforestière et expérimentation en boisement intensif dans les savanes du nord de la Côte d'Ivoire. Rapport d'activité 1990 de l'Antenne CTFT de Korhogo. Côte d'Ivoire, CTFT-Cirad, 8 p. + annexes (53 p.).

Louppe D., Ouattara N., Koffi O., Lebahy C., 1992. Station Kamonon Diabaté : Protocoles expérimentaux et comptes rendus d'installation des essais de 1988 à 1991. IDEFOR-DFO, Antenne de Korhogo. Côte d'Ivoire, CTFTCirad, 175 p. https://agritrop.cirad.fr/334767/1/document 334767.pdf

Louppe D., Ouattara N., Koffi O., 1993. Institut des forêts, Département foresterie. Antenne de Kothogo. Rapport d'activité, année 1992. Korhogo, Côte d'Ivoire, IDEFOR-DFO, $76 \mathrm{p}$.

Louppe D., Ouattara N., 1993. Croissance en plantation de quelques espèces ligneuses locales. Korhogo, Côte d'Ivoire, IDEFOR-DFO, 12 p. https://agritrop.cirad. $\mathrm{fr} / 336817 /$

Louppe D., 1994. Division de recherches en zone de savanes - Rapport d'activités 1993. Korhogo, Côte d'Ivoire, IDEFOR-DFO, 15 p. https://agritrop.cirad. fr/311992/1/ID311992.pdf

Louppe D., M'Bla K., Coulibaly A., 1994a. Tarifs de cubage pour Afzelia africana en forêt de Badénou (Nord Côte d'Ivoire). Korhogo, Côte d'Ivoire, IDEFOR-DFO, 16 p. + annexes. https://agritrop.cirad.fr/311991/1/ document 311991.pdf

Louppe D., M’Bla K., Coulibaly A., 1994b. Tarifs de cubage pour Anogeissus leïocarpus en forêt de Badénou (Nord Côte d'Ivoire). Korhogo, Côte d'Ivoire, IDEFOR-DFO, 12 p. + annexes. https://agritrop.cirad.fr/311994/1/ID311994. pdf

Louppe D., M'Bla K., Coulibaly A., 1994c. Tarifs de cubage pour Pterocarpus erinaceus en forêt de Badénou (Nord Côte d'Ivoire). Korhogo, Côte d'Ivoire, IDEFOR-DFO, 12 p. + annexes. https://agritrop.cirad.fr/311989/1/ID311989. pdf 
Louppe D., M’Bla K., Coulibaly A., 1994d. Relations dendrométriques préliminaires pour six espèces ligneuses secondaires de la forêt de Badénou (Nord Côte d'Ivoire). Korhogo, Côte d'Ivoire, IDEFOR-DFO, 39 p. https://agritrop.cirad.fr/311990/1/document 311990.pdf

Louppe D., Ouattara N., M’Bla K., Coulibaly A., 1995. Rapport annuel d'activités 1994. Korhogo, Côte d'Ivoire, IDEFOR-DFO, 42 p. https://agritrop.cirad.fr/312520/6/ ID312520.pdf

Louppe D., Ouattara N., 1996a. Station Kamonon Diabaté (Korhogo) - Résultats des mensurations de 1996. Korhogo, Côte d'Ivoire, IDEFOR-DFO, 54 p. https://agritrop.cirad. fr/581425/1/1996\%20Recherche \%20forestières $\% 20$ Korhogo\%20Résultats\%20des\%20mesures\%20D\%20 LOUPPE.pdf

Louppe D., Ouattara N., 1996b. Les arboretums d'espèces locales en Nord Côte d'Ivoire - Résultats des mesures de 1996. Korhogo-Abidjan, Côte d'Ivoire, IDEFOR-DFO/Cirad-Forêt, 17 p. https://agritrop.cirad. $\mathrm{fr} / 581418 / 1 / 1996 \% 20$ Arboretums $\% 20$ espèces $\% 20$ locales\%20Korhogo\%20D\%20LOUPPE.pdf

Louppe D., Ouattara N'K., 1997. Croissance en plantation de quelques essences ligneuses du Nord de la Côte d'Ivoire. In : $11^{\mathrm{e}}$ Congrès forestier mondial. Synthèse « après-congrès ». Antalya, Turquie, 13 octobre 1997/22 octobre 1997. Montpellier, France, Cirad-Forêt, 9 p. http://agritrop.cirad.fr/389684/

von Maydell H. J., 1983. Arbres et arbustes du Sahel, leurs caractéristiques et leurs utilisations. Eschborn, Allemagne, Deutsche Gesellschaft für Technische Zusammenarbeit, 532 p. https://permaculture-sans-frontieres. org/sites/default/files/docs_pdf/\%20Arbres $\% 20$ et $\% 20$ arbustes $\% 20$ du $\% 20$ Sahel. $\% 20$ Leurs $\% 20$ caracte $\%$ CC\%81ristiques\%20et\%20leurs\%20utilisations\%20-\%20 H.-J.\%20von\%20Maydell\%20\%28FR\%29\%20.pdf

Michel L., Vilardebo A., 1961. Les nématodes associés aux bananiers cultivés dans l'Ouest africain. I. Espèces parasites. Dommages causés. Fruits, 16 (5) : 205-219. https://agritrop.cirad.fr/457656/

Peltier R., 1987. Centre de recherches forestières de Nkolbisson. Antenne de Maroua - Résultats des essais sylvicoles - mesures 86-87. Cameroun, IRA, 201 p. https:// agritrop.cirad.fr/320878/

Peltier R., 1993. Note de visite au Burkina-Faso du 22 au 25/02/1993. Nogent-sur-Marne, France, Cirad-Forêt, 13 p. https://agritrop.cirad.fr/594083/1/ID594083.pdf

Roussel J., 1995. Pépinières et plantations forestières en Afrique tropicale sèche : manuel à l'usage des ingénieurs et techniciens du reboisement. Dakar, Sénégal, ISRA, 435 p. https://agritrop.cirad.fr/313550/

Sanogo S., 2015. Essais de germination et conservation de fruits et graines de quelques espèces ligneuses à usages multiples au Mali. Thèse de doctorat (PhD), Faculté des sciences en bio-Ingénierie, Université de Gand, Belgique. https://biblio.ugent.be/publication/6843900/ file/6843905.pdf
Seignobos C., 1996. Faidherbia albida élément descripteur d'agrosystèmes. L'exemple du Nord-Cameroun. In : Peltier R. (éd.). Les parcs à Faidherbia albida. Montpellier, France, Cirad-Forêt, Cahiers scientifiques $\mathrm{n}^{\circ}$ 12, 153-169. https://ur-forets-societes.cirad.fr/ content/download/4143/32374/version/1/file/Partie+3-9-+Les+parcs+a+Faidherbia-Faidherbia+albida+element+decrypteur+d agrosystemes-Seignobos.pdf

Stembert I., 1991. Essais de prétraitements de graines d'espèces forestières tropicales en vue de la réalisation de haies-vives par semis mécanique. Travail de fin d'études pour l'obtention du diplôme d'ingénieur des Eaux et Forêts à la Faculté des sciences agronomiques de l'État à Gembloux, Belgique. FSAGx-CTFT-Cl, 83 p.

Vincenti O., 1986. Vingt ans de recherches forestières en Basse Casamance. Ziguinchor, Sénégal, Direction des recherches sur les productions forestières (ISRA). Non publié.

Willan R. L., 1992. Guide de manipulation des semences forestières dans le cas particulier des régions tropicales. Rome, Italie, FAO, 444 p. http://www.fao.org/3/AD232F/ ad232f00.htm

\begin{tabular}{|c|c|}
\hline \multicolumn{2}{|c|}{ Louppe et al. - Contribution des auteurs } \\
\hline Rôle du contributeur & Noms des auteurs \\
\hline Conceptualisation & D. Louppe, N. Ouattara \\
\hline Méthodologie & D. Louppe, N. Ouattara \\
\hline Récolte des graines & N. Ouattara \\
\hline Pépinière et plantation & N. Ouattara, D. Louppe \\
\hline Gestion des plantations & $\begin{array}{l}\text { N. Ouattara, D. Louppe, } \\
\text { A. N. Kanga, B. Coulibaly }\end{array}$ \\
\hline Mesures & $\begin{array}{l}\text { N. Ouattara, D. Louppe, A. N. Kanga, } \\
\text { I. Zo-Bi, F. Tiéoulé, A. Ahoba, } \\
\text { B. Hérault }\end{array}$ \\
\hline Gestion des données & $\begin{array}{l}\text { D. Louppe, B. Hérault, } \\
\text { I. Zo-Bi, A. Ahoba }\end{array}$ \\
\hline Analyse formelle & D. Louppe, B. Hérault \\
\hline $\begin{array}{l}\text { Écriture - Préparation } \\
\text { de l'ébauche originale }\end{array}$ & D. Louppe \\
\hline $\begin{array}{l}\text { Écriture - Révision et } \\
\text { édition }\end{array}$ & $\begin{array}{l}\text { D. Louppe, N. Ouattara, } \\
\text { I. Zo-Bi, A. Ahoba }\end{array}$ \\
\hline
\end{tabular} \\ Louppe et al. - Contribution des auteurs}

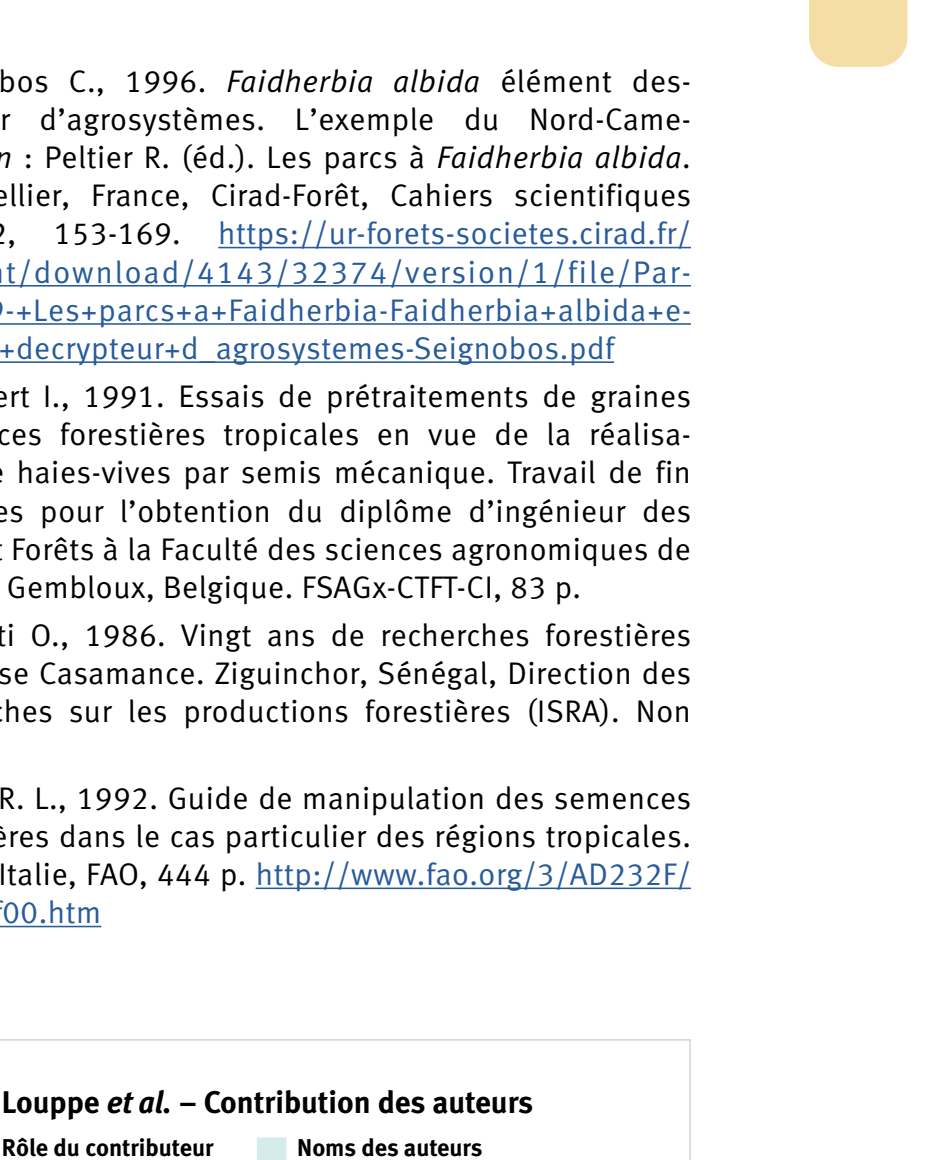

Bois et Forêts des Tropiques - Revue scientifique du Cirad (c) Bois et Forêts des Tropiques ( $)$ Cirad

Cirad - Campus international de Baillarguet, 34398 Montpellier Cedex 5, France - Contact : bft@cirad.fr - ISSN : L-0006-579X 